\title{
Global change: state of the science
}

\author{
D.J. Wuebbles ${ }^{\mathrm{a}, *}$, A. Jain ${ }^{\mathrm{a}}, \mathrm{J}_{\text {. Edmonds }}{ }^{\mathrm{b}}$, D. Harvey ${ }^{\mathrm{c}}$, K. Hayhoe ${ }^{\mathrm{a}, \mathrm{c}}$ \\ a Department of Atmospheric Sciences, University of Illinois, Urbana, IL 61801, USA \\ ${ }^{\mathrm{b}}$ Pacific Northwest National Laboratory, Washington, DC 20024-2115, USA \\ ${ }^{\mathrm{c}}$ Department of Geography, University of Toronto, Toronto, Canada
}

Received 15 November 1998; accepted 22 March 1999

\begin{abstract}
Only recently, within a few decades, have we realized that humanity significantly influences the global environment. In the early 1980s, atmospheric measurements confirmed basic concepts developed a decade earlier. These basic concepts showed that human activities were affecting the ozone layer. Later measurements and theoretical analyses have clearly connected observed changes in ozone to human-related increases of chlorine and bromine in the stratosphere. As a result of prompt international policy agreements, the combined abundances of ozone-depleting compounds peaked in 1994 and ozone is already beginning a slow path to recovery. A much more difficult problem confronting humanity is the impact of increasing levels of carbon dioxide and other greenhouse gases on global climate. The processes that connect greenhouse gas emissions to climate are very complex. This complexity has limited our ability to make a definitive projection of future climate change. Nevertheless, the range of projected climate change shows that global warming has the potential to severely impact human welfare and our planet as a whole. This paper evaluates the state of the scientific understanding of the global change issues, their potential impacts, and the relationships of scientific understanding to policy considerations. (C) 1999 Elsevier Science Ltd. All rights reserved.
\end{abstract}

Keywords: Global climate change; Ozone; Greenhouse gasses

\section{Introduction}

Until only a matter of decades ago, few scientists had the insight to recognize that human activities could actually lead to environmental changes on a scale that would impact the entire planet. The Swedish chemist Svelte Arrhenius in 1896 suggested the possibility of major changes in the climate if greenhouse gas concentrations were to increase, but he had no real basis to expect such an increase. More typical is the writing of John Muir at the turn of the century. While lamenting the destruction of the environment, Muir consoled himself with the knowledge that humans could not harm the atmosphere (Keller, 1998).

Increasing world population and corresponding developments in technology have revealed the falsity of such views. Significant increases in the emissions and concentrations of atmospheric gases and particles can have and are having serious effects on the global atmosphere.

\footnotetext{
* Corresponding author. Fax: + 1-217-244-4393.

E-mail address: wuebbles@atmos.uiac.edu (D.J. Wuebbles)
}

Of particular concern to global change are the possible impacts of human activities on the ozone layer and on climate.

The ozone layer is a term that refers to the distribution of ozone that is naturally formed in the stratosphere. This layer protects life on Earth from harmful levels of solar ultraviolet radiation. Chlorofluorocarbons (CFCs) and other chlorinated and brominated halocarbons are emitted from a variety of human activities. Atmospheric measurements have clearly corroborated theoretical studies showing that the chlorine and bromine released from the destruction of these halocarbons in the stratosphere is reacting to destroy ozone (e.g. WMO, 1995, 1998).

Climate is defined as the typical behavior of the atmosphere, the aggregation of the weather, and is generally expressed in terms of averages and variances of temperature, precipitation and other physical properties. Climate is being affected by human activities that emit radiatively active substances such as greenhouse gases or aerosol particles. Greenhouse gases in the atmosphere absorb infrared radiation, especially in the 'atmospheric window' region from 8 to $12 \mu \mathrm{m}$, that 
would otherwise escape to space. This trapped radiation warms the atmosphere, creating a positive radiative forcing which in turn warms the Earth's surface. Aerosols, on the other hand, scatter or absorb solar radiation and prevent it from reaching the Earth. This has a net cooling effect. Together, emissions of greenhouse gases and aerosols from human activities destroy the existing radiative balance of the atmosphere and alter the heating and cooling rate of the Earth. This is what can cause climate change.

A common feature of the gases of most concern to global ozone and climate are their atmospheric lifetimes, generally ranging from years to hundreds of years. These lifetimes are relatively long compared to most other trace gases in the atmosphere. The long lifetime of these gases allows them to reach the stratosphere, where they can affect ozone. It also allows them to build atmospheric concentrations large enough such that the amount of infrared radiation they absorb can influence climate. On the other hand, atmospheric particles such as sulfate or carbonaceous aerosols have relatively short atmospheric lifetimes, on the order of days to weeks. They can still affect climate because of their size and effectiveness at scattering or absorbing radiation.

What these gases do not have in common is the way their emissions have been treated. Production and emissions of the recognized harmful chemicals have been eliminated as a result of national and international policy to protect the ozone layer. Replacements that do not significantly affect ozone have generally been found for the important societal uses of CFCs and the other halocarbons. In contrast, little has been done to reduce emissions of greenhouse gases that can affect climate. The connection between ozone depletion and CFC and halocarbon emissions are measurable and the evidence substantial, while the effects of human activities on climate are more difficult to establish.

Despite the fact that the largest changes in climate are expected to occur decades from now, evidence for human-induced climate change is building. One indication is the well-caveated statement made by the 1996 Intergovernmental Panel on Climate Change (IPCC 1996a) scientific assessment: "...the balance of evidence suggests that there is discernible human influence on global climate. (p. 5)" IPCC (1996a, b, c). Even so, measures to control the concentration of carbon dioxide $\left(\mathrm{CO}_{2}\right)$, the greenhouse gas of most concern, will require major reductions in emissions from fossil fuel burning as well as major changes in global energy use (IPCC, 1996a, c; Hoffert et al., 1999).

This paper provides an overview of the current state of scientific understanding on ozone and climate issues. Many other important issues such as biodiversity and acid rain are also related to global change. However, these topics are beyond the scope of this review and will not be discussed here. The first section of this paper describes the major gases affecting climate, the changes occurring in atmospheric concentrations of these gases, and the driving forces behind these changes. The following sections describe the current understanding of the changes occurring to ozone and climate and the projections for future changes. We conclude with a discussion of the concerns about impacts of climate change and the ongoing policy considerations relating to these concerns.

\section{Atmospheric gases: emissions and concentrations}

Without human intervention, concentrations of greenhouse gases important to global change would be expected to change slowly, as indicated by ice core measurements before the last century. However, since the beginning of the industrial age, emissions associated with human activities have risen rapidly. Agriculture, industry, waste disposal, deforestation, and especially fossil fuel use have been producing increasing amounts of $\mathrm{CO}_{2}$, methane $\left(\mathrm{CH}_{4}\right)$, nitrous oxide $\left(\mathrm{N}_{2} \mathrm{O}\right)$, CFCs and other important gases. Due to increasing emissions, atmospheric levels of these gases have been building at an unprecedented rate, raising concerns regarding the impact of these gases on ozone and climate. Some of the gases, such as CFCs, are particularly effective at depleting ozone. All of the gases considered in this section are greenhouse gases with potential radiative influences on climate. Of these gases, $\mathrm{CO}_{2}$ and $\mathrm{CH}_{4}$, to a lesser extent-is of particular concern to climate change.

\section{1. $\mathrm{CO}_{2}$}

Two types of human activities are primarily responsible for emissions of $\mathrm{CO}_{2}$ : fossil fuel use, which released about $6.0 \mathrm{GtC}^{1}$ into the atmosphere in 1990, and land use, including deforestation and biomass burning, which may have contributed about $1.6 \pm 1.0 \mathrm{GtC}$ in addition to that from fossil fuels (IPCC, 1995, 1996a).

\subsubsection{Emissions from fossil fuel consumption}

$\mathrm{CO}_{2}$ is emitted when carbon-containing fossil fuels are oxidized by combustion. $\mathrm{CO}_{2}$ emissions depend on energy and carbon content, which ranges from 13.6 to 14.0 $\mathrm{MtC} / \mathrm{EJ}^{2}$ for natural gas, 19.0 to 20.3 for oil, and 23.9 to 24.5 for coal (High Heating Values; Nakicenovic et al., 1996). Other energy sources such as hydro, nuclear, wind, and solar have no direct carbon emissions. Biomass energy, however, is a special case. When biomass is used as a fuel it releases carbon with a carbon-to-energy ratio similar to that of coal. However,

\footnotetext{
${ }^{1} \mathrm{GtC}=$ gigatons of carbon $=10^{9}$ tommes of carbon.

${ }^{2} \mathrm{MtC} / \mathrm{EJ}=$ megatons of carbon per exajoule $=10^{6}$ tons of carbon per $10^{18}$ joules of energy.
} 
the biomass has already absorbed an equal amount of carbon from the atmosphere prior to its emission, so that net emissions of carbon from biomass fuels are zero over its life cycle.

Anthropogenic or human emissions from fossil fuel use have been estimated as far back as 1751 (Fig. 1). Before 1863, emissions did not exceed $0.1 \mathrm{GtC} /$ year. However, by 1995 they had reached $6.5 \mathrm{GtC} /$ year, giving an average emissions growth rate slightly greater than $3 \%$ per year over the last two and a half centuries.
Recent growth rates have been significantly lower, at $1.8 \%$ per year between 1970 and 1995 .

Emissions were initially dominated by coal (Fig. 1). Since 1985, liquids have been the main source of emissions despite their lower carbon intensity. The regional pattern of emissions has also changed (Fig. 2). Once dominated by Europe and North America, developing nations are providing an increasing share of emissions. In 1995, non-Annex I nations accounted for $48 \%$ of global emissions.

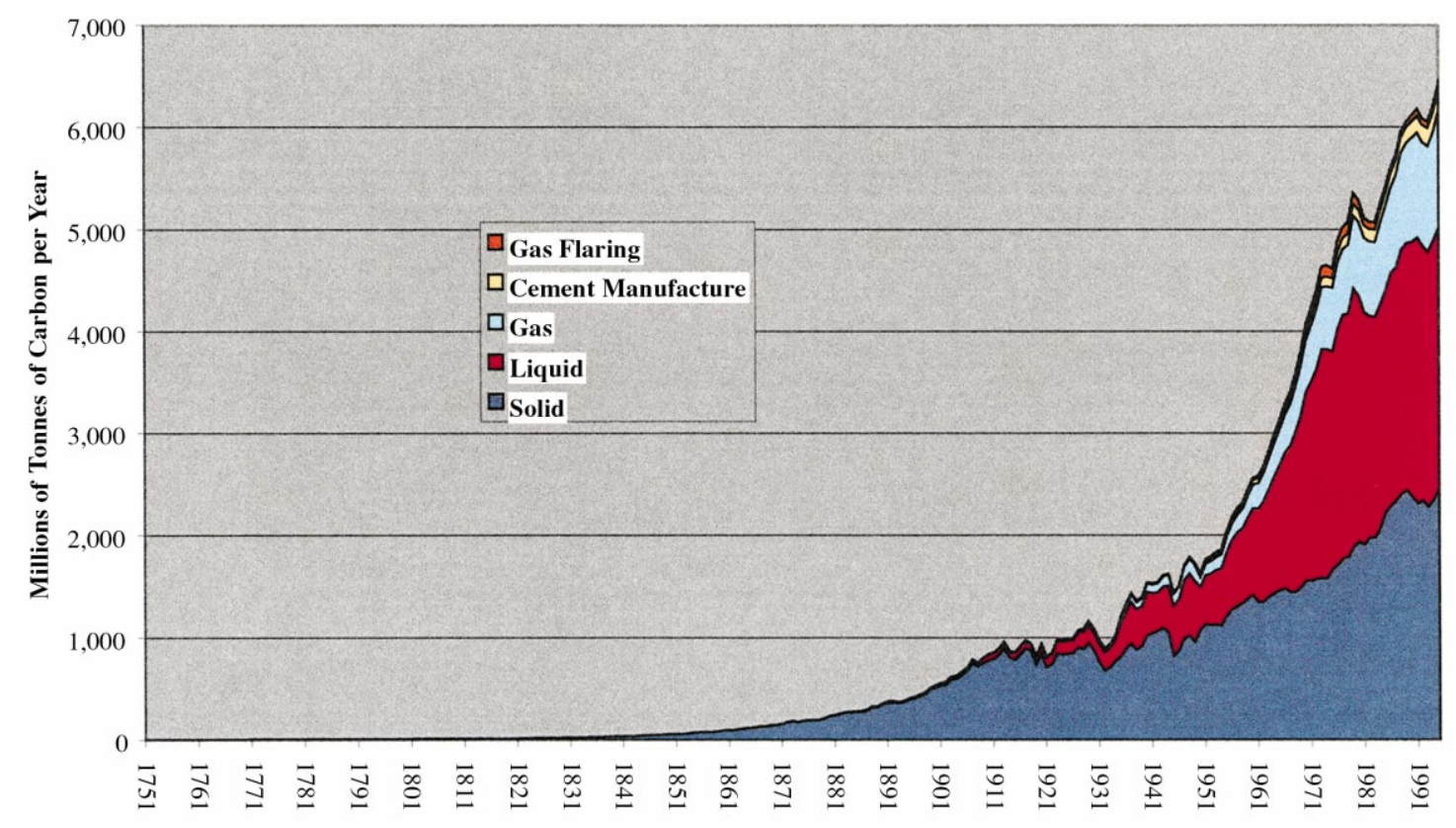

Fig. 1. Global emissions of carbon from fossil fuels and cement manufacture: 1771-1995 (Source: CDIAC web site: http://cdiac.esd.ornl.gov/cdiac/).

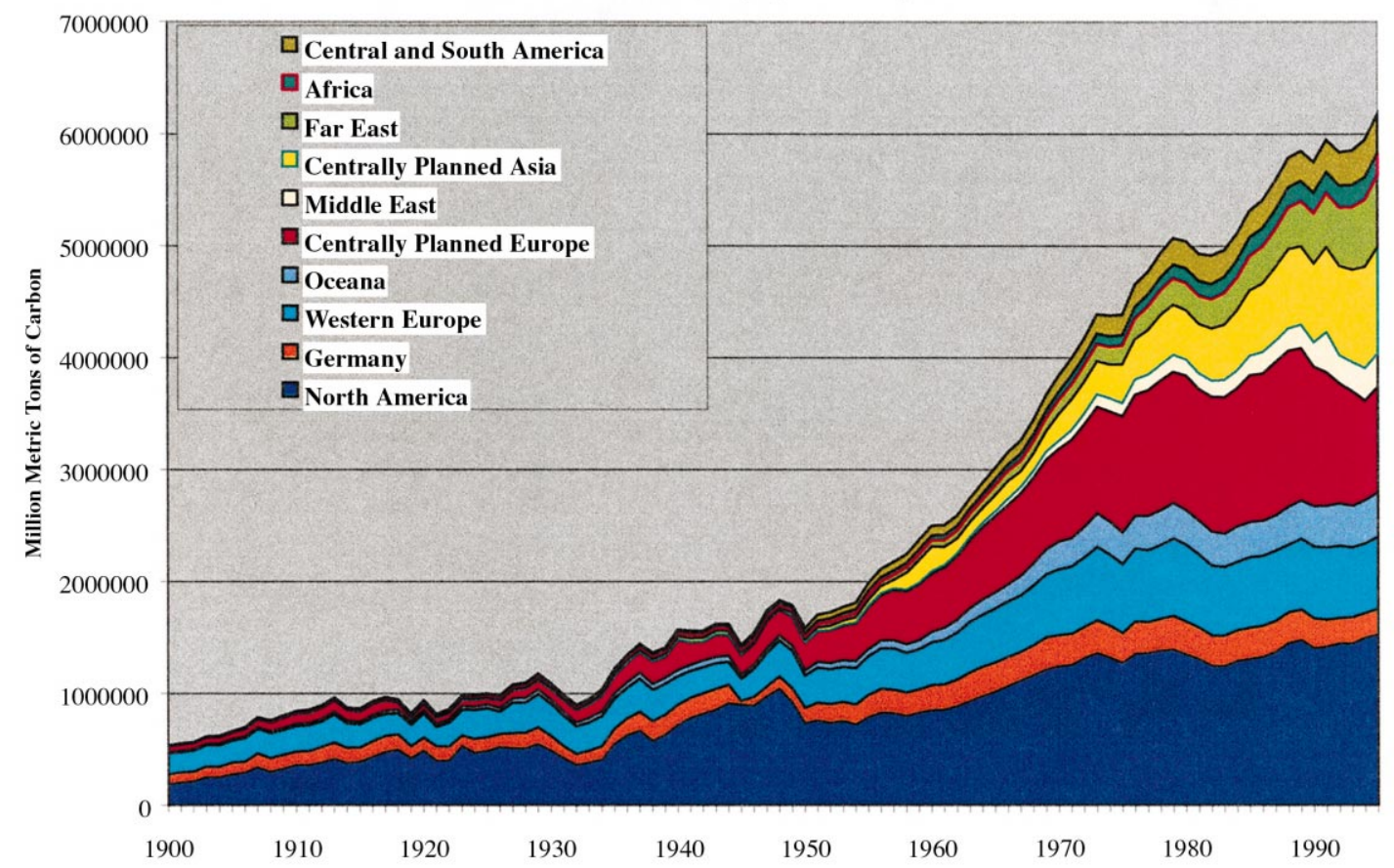

Fig.2. Regional carbon emissions from fossil fuel and cement: 1900-1995 (Source: CDIAC web site: http://cdiac.esd.ornl.gov/cdiac/). 


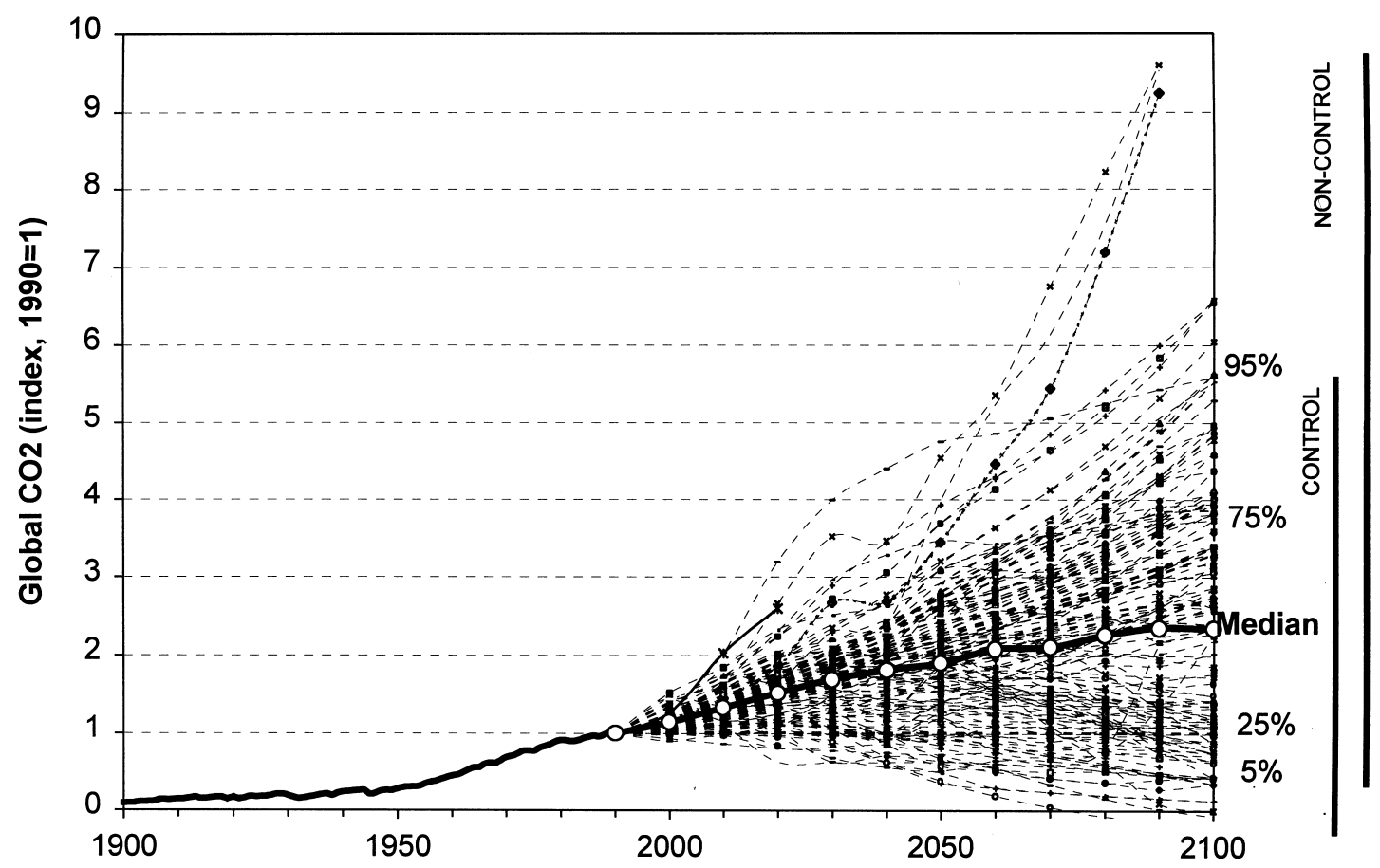

Fig. 3. Global carbon emissions, historical development and in scenarios. The emissions paths indicate a wide range of future emissions. The range is also large in the base year 1990. In order to separate the variation due to base-year specification from different future paths, emissions are indexed for the year 1990, when actual global energy-related $\mathrm{CO}_{2}$ emissions were about $6 \mathrm{GtC}$. The 'error' bar placed superimposed on the 1990 indexed emissions indicates the base-year range across the scenarios in the database. Altogether, 232 different scenarios from the database are included in the figure. Two vertical bars on the right-hand side indicate the ranges for scenarios with emissions control measures (labeled "control") and for those without controls ("non-control"). Data sources: Nakicenovic et al. (1998); Morita and Lee (1998); Nakicenovic (1999).

\subsubsection{Projections of future carbon emissions}

Fossil fuel carbon emissions are anticipated to grow over the course of the twenty-first century as a natural consequence of a growing global energy system.Fig. 3 shows the great variety in the forecasts that have appeared in the literature. The anticipated growth in emissions reflects optimism with regard to underlying economic growth, particularly in the presently developing world. This in turn implies a rapidly expanding global energy system.

Fossil fuels are the dominant energy provider in the present world. More than $85 \%$ of the world's energy is provided by fossil fuels. This composition is anticipated to change over time. Renewable energy technologies are envisioned to provide an increasing share of total energy. A few scenarios even anticipate that, in the absence of climate policy intervention, fossil fuel use will decline over the course of the twenty-first century. The six scenarios developed for the IPCC by Leggett et al. (1992) are displayed in Fig. 4.

While oil is the dominant fossil fuel in 1995, most future scenarios anticipate a transition towards coal. This transition is the consequence of a limited conventional oil and gas resource base. The relatively low estimates of conventional oil and gas emissions growth (in comparison to coal) over the course of the next century reflect the present knowledge and expectations of resource occurrences. Table 1 shows present estimates and ranges of fossil fuel resources in terms of their carbon content. The carbon content of coal is an order of magnitude greater than the estimated carbon content of conventional oil and gas combined. The range of potential oil and gas resources roughly doubles when additional occurrences are included, although additional occurrences also expand the range of coal resource estimates by a factor of two. Unconventional gas resources are approximately twice the total of conventional gas resources, leaving a potential oil and gas resource base of more than $1500 \mathrm{GtC}$. The availability of tar sands and heavy oils would bring the total carbon in oil and gas resources to more than $2000 \mathrm{GtC}$.

For comparison, Table 2 shows cumulative emissions from 1990 to 2100 associated with various ceilings for $\mathrm{CO}_{2}$ concentrations. Conventional oil and gas resources alone, even with the inclusion of additional occurrences, are insufficient to sustain a concentration of $450 \mathrm{ppmv}^{3}$. Only with the inclusion of unconventional resources is there sufficient carbon in oil and gas resources to exceed emissions for stabilization of concentrations below $550 \mathrm{ppmv}$ using the Wigley et al. (1996) (WRE) emissions paths.

Unconventional resources should not be ignored, however. An alternative plausible development of future energy systems can be constructed on the assumption that the cost of presently unconventional oil and gas

\footnotetext{
${ }^{3}$ ppmv $=$ Parts per million $\left(10^{6}\right)$ by volume
} 

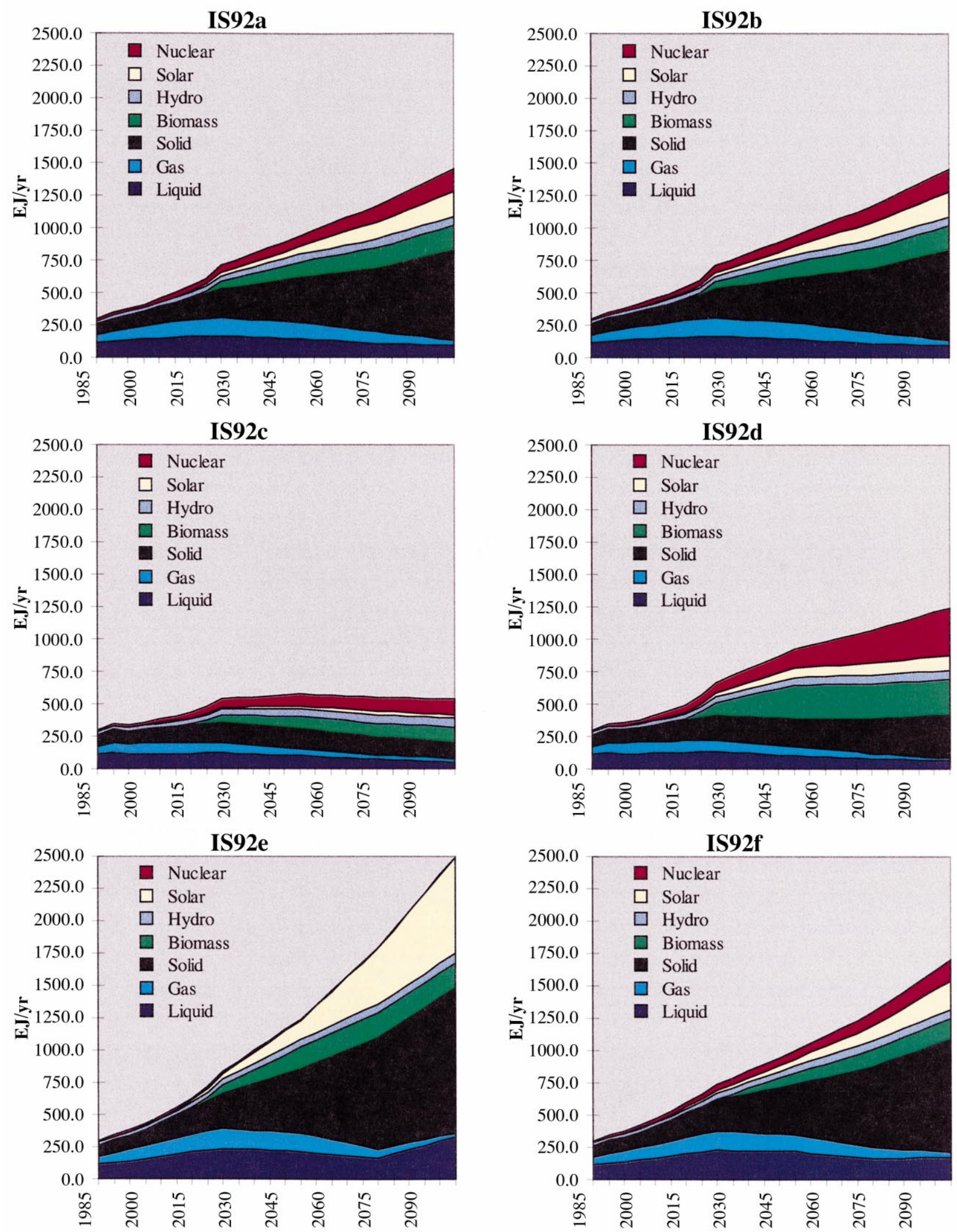

Fig. 4. Projections of annual fossil fuel emissions corresponding to IS92 scenarios a-f. Based on IPCC (1992; 1995). 
Table 1

Carbon content of fossil fuel energy resources potentially available after 1990

\begin{tabular}{lclcr}
\hline Energy form & $\begin{array}{l}\text { Resource } \\
\text { base }(\operatorname{PgC})\end{array}$ & $\begin{array}{l}\text { Range of resource } \\
\text { base estimates }(\operatorname{PgC})\end{array}$ & $\begin{array}{l}\text { Additional } \\
\text { occurrences }(\operatorname{PgC})\end{array}$ & $\begin{array}{l}\text { Resources plus additional } \\
\text { occurrences }(\operatorname{PgC})\end{array}$ \\
\hline Conventional oil $^{\mathrm{a}}$ & 170 & $156-230$ & 200 & $156-430$ \\
Conventional gas $^{\mathrm{a}}$ & 140 & $115-240$ & 150 & $115-390$ \\
Unconventional gas $^{\mathrm{a}}$ & 410 & - & 340 & 750 \\
Coal $^{\mathrm{a}, \mathrm{b}, \mathrm{c}}$ & 3,240 & - & 3350 & $3240-6590$ \\
Tar sands and heavy oils $^{\mathrm{c}, \mathrm{d}}$ & 720 & $600-800$ & - & $600-800$ \\
Oil shale $^{\mathrm{c}, \mathrm{e}}$ & 40,000 & - & 12,240 & 40,000 \\
Gas hydrates $^{\mathrm{a}}$ & - & - & & 12,240 \\
\hline
\end{tabular}

a IPCC (1996c) p. 87.

b Assumes 50\% unrecoverable coal in the resource base.

c Range estimates are not available due to the abundance of the resource.

d Rogner (1996).

e Edmonds and Reilly (1985).

Table 2

Cumulative carbon emissions 1990-2100 Under WRE $\mathrm{CO}_{2}$ stabilization $^{\mathrm{a}}$

\begin{tabular}{lc}
\hline Concentration ceiling & $\begin{array}{l}\text { Cumulative } \\
\text { emissions } 1990-2100(\operatorname{PgC})\end{array}$ \\
\hline 350 & 363 \\
450 & 714 \\
550 & 1043 \\
650 & 1239 \\
750 & 1348 \\
\hline
\end{tabular}

a Based on Wigley et al. (1996).

resources declines to competitive levels. This has the result of lowering the overall cost of energy, raising future global energy usage, but also lowering the carbonto-energy ratio. These two offsetting factors imply that the range of reference case fossil fuel carbon emissions is unlikely to change significantly, but the underlying story may change dramatically.

A second major feature of reference scenarios is an increasing share of emissions associated with presently developing nations. The pattern developed by IS92a is shown in Fig. 5. Between 1985 and 2100 the share of carbon emissions from Annex I nations (OECD plus Eastern Europe and the former Soviet Union) declines from 58 to $31 \%$.

\subsubsection{Emissions from land-use changes}

There are approximately $560 \mathrm{GtC}$ in the form of above-ground biomass, and an additional $1200 \mathrm{GtC}$ in soils and detritus. These pools form the principal reservoirs from which terrestrial systems can exhaust or sequester carbon. They vary greatly, though long-term emissions are bounded and most trajectories show little or no net emission of carbon from these pools by the end of the twenty-first century. Land-use emissions scenarios do not project emission levels on a scale similar to fossil fuel carbon emissions (IPCC, 1995).

Cumulative emissions estimates from land-use change range from 30 to $320 \mathrm{GtC}$ over the years 1990 to 2100 , with afforestation scenarios estimating net uptake in the range $30-150 \mathrm{GtC}$. In contrast, the range of cumulative

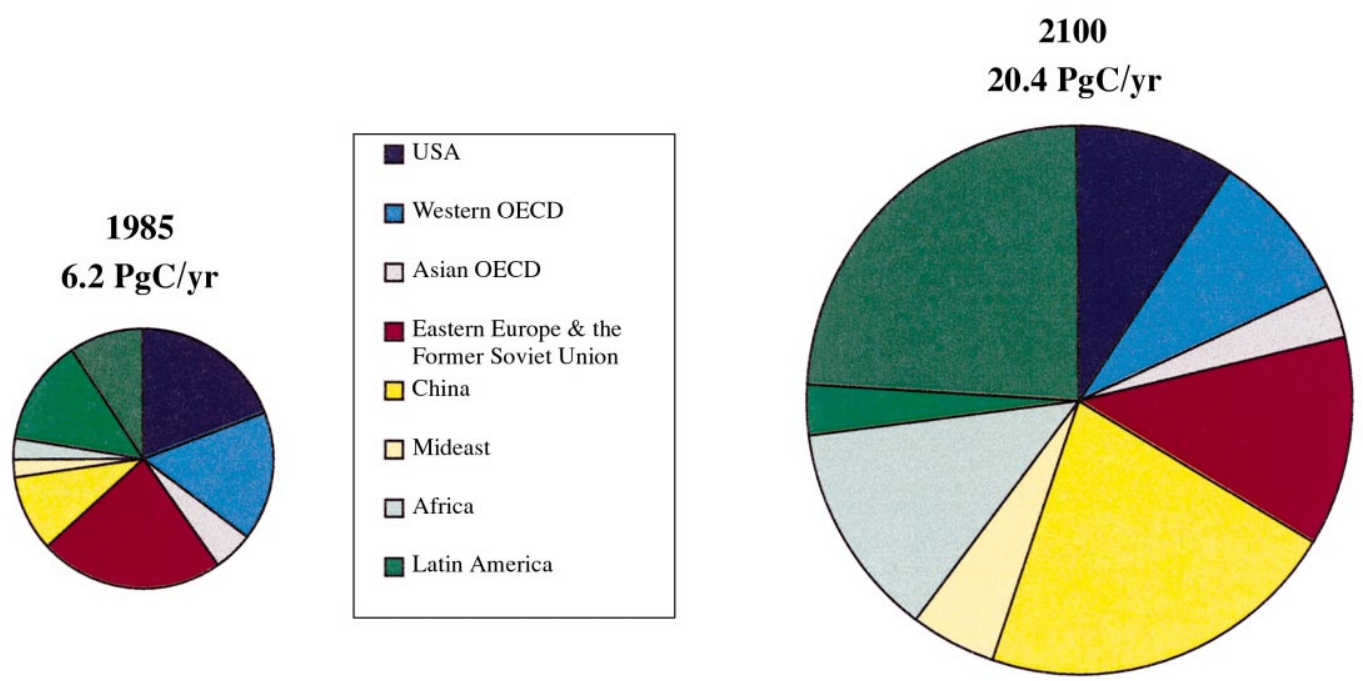

Fig. 5. Comparison of regional breakdown of carbon emissions in 1985 versus projected regional emissions in 2100. Based on IPCC (1992, 1995, 1996a). 
emissions from published fossil fuel emissions scenarios range from as little as $490 \mathrm{GtC}$ to $3450 \mathrm{GtC}$ over that same 110-year period (IPCC, 1995).

\subsubsection{Historical $\mathrm{CO}_{2}$ concentrations}

Accurate measurements of atmospheric $\mathrm{CO}_{2}$ concentration began in 1958 at the Mauna Loa Observatory in Hawaii (Keeling et al., 1976). Fig. 6 shows that the annually averaged concentration of $\mathrm{CO}_{2}$ in the atmosphere has risen from 316 ppmv in 1959 to 364 ppmv in 1997 (Keeling and Whorf, 1998). The $\mathrm{CO}_{2}$ measurements exhibit a seasonal cycle, which is mainly caused by the seasonal uptake and release of atmospheric $\mathrm{CO}_{2}$ by terrestrial ecosystems.

The added atmospheric carbon resulting from human activities, as described above, is redistributed within the atmospheric, oceanic, and biospheric parts of the global carbon cycle, with the dynamics of this redistribution determining the corresponding rise in atmospheric $\mathrm{CO}_{2}$ concentration. Atmospheric $\mathrm{CO}_{2}$ increased at the rate of $3.4 \pm 0.2 \mathrm{GtC} /$ year during the $1980 \mathrm{~s}$. Recent analyses of oceanic and atmospheric data indicate that the likely rate of oceanic uptake is $2.0 \pm 0.8 \mathrm{GtC} /$ year (IPCC, 1992, 1995, 1996a), although some have argued that the uncertainty is larger than $\pm 0.8 \mathrm{GtC} /$ year (e.g., Tans et al., 1990). In the future, as the amount of $\mathrm{CO}_{2}$ increases in the atmosphere and in the ocean, it is expected that the oceans will take up a smaller percentage of the new emissions.

Analyses of the carbon budget (IPCC, 1990; Tans et al., 1990) have implied that there is a mismatch between observed levels of $\mathrm{CO}_{2}$ and known loss processes. This discrepancy suggests that a missing carbon sink has existed during recent decades. This sink now appears to be best explainable in terms of increased net carbon storage by the terrestrial biomass stimulated by the $\mathrm{CO}_{2}$

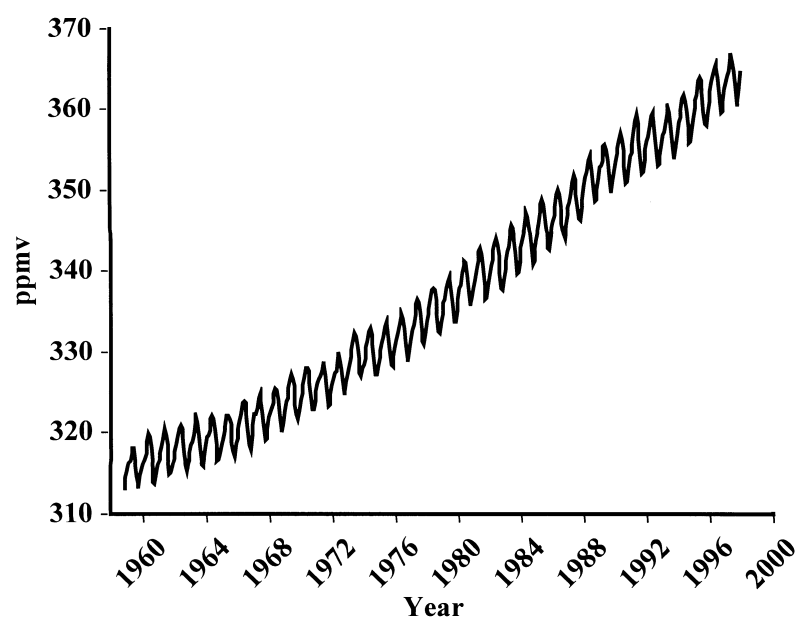

Fig. 6. Observed monthly average $\mathrm{CO}_{2}$ concentration (ppmv) from Mauna Loa, Hawaii (Keeling and Warf, 1998). Seasonal variations are primarily due to the uptake and production of $\mathrm{CO}_{2}$ by the terrestrial biosphere. fertilization effect and other processes (IPCC, 1995, 1996a). Based on the calculated ocean uptake rate, together with estimated fossil emissions and the observed atmospheric inventory change, the terrestrial biosphere uptake in the 1980 s was $1.3 \pm 1.5 \mathrm{GtC} /$ year.

\section{2. $\mathrm{CH}_{4}$}

\subsection{1. $\mathrm{CH}_{4}$ sources}

$\mathrm{CH}_{4}$ differs from $\mathrm{CO}_{2}$ in that it is released into the atmosphere by a number of sources, both natural and anthropogenic. Anthropogenic emissions arise from biogenic sources related to agriculture and waste disposal, including enteric fermentation, animal and human wastes, rice paddies, biomass burning, and landfills. Emissions also result from fossil fuel-related $\mathrm{CH}_{4}$ sources such as natural gas loss, coal mining, and the petroleum industry. $\mathrm{CH}_{4}$ is emitted naturally by wetlands, termites, other wild ruminants, oceans, and hydrates. Based on recent estimates, current human-related biogenic and fossil fuel-related sources for $\mathrm{CH}_{4}$ are approximately 275 and $100 \mathrm{TgCH}_{4} /$ year ${ }^{4}$, while total natural sources are around $160 \mathrm{TgCH} 4 / \mathrm{yr}$ (IPCC, 1996a).

Due to the variety of $\mathrm{CH}_{4}$ sources, emissions are affected by numerous factors, including energy use, human population distributions, agricultural practices, and climate. These factors complicate the resolution of past emissions and make predictions of future $\mathrm{CH}_{4}$ emissions difficult. Estimates of historical $\mathrm{CH}_{4}$ emissions can be obtained by top-down analyses of past measurements of atmospheric $\mathrm{CH}_{4}$ concentrations, such as that of Khalil and Rasmussen (1994) [Fig. 7(a)]. Past emissions can also be calculated by bottom-up analyses such as that of Hayhoe (1997) which attempt to capture the effect of these factors on emissions. Fig. 7(b) shows that although $\mathrm{CH}_{4}$ emissions have climbed rapidly over the past four decades, the relative importance of agricultural sources may be declining, with non-agricultural sources related to fossil fuel use and waste disposal on the increase. Future scenarios of methane emissions have been developed by the IPCC (1996a) based on projections of population, agricultural demand, land use, and energy consumption. Fig. 8(a) and (b) show that $\mathrm{CH}_{4}$ emissions may or may not increase at the same rate in the future, depending on various influences such as changes in agricultural productivity or in gas utilization from waste disposal.

\subsubsection{Historical concentrations}

Although its atmospheric abundance is less than $0.5 \%$ that of $\mathrm{CO}_{2}$, on a molecule by molecule basis, $\mathrm{CH}_{4}$ is approximately 50 times more effective at absorbing infrared radiation than $\mathrm{CO}_{2}$ (IPCC, 1996a). This, coupled with

\footnotetext{
${ }^{4} \mathrm{TgCH}_{4}=$ teragrams of methane $=10^{12}$ grams of $\mathrm{CH}_{4}=10^{6}$ tons of $\mathrm{CH}_{4}$ of $\mathrm{MtCH}_{4}$.
} 

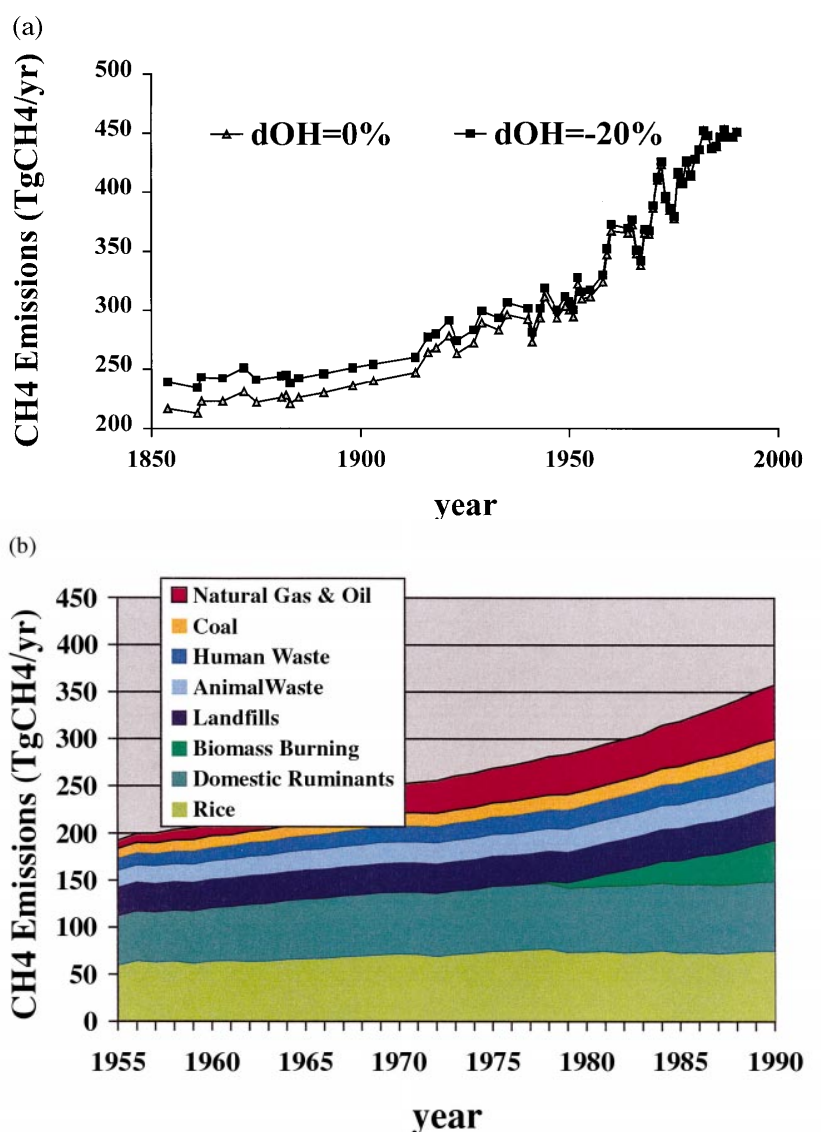

Fig. 7. (a) Historical $\mathrm{CH}_{4}$ emissions from 1750-1993 based on measurements of atmospheric $\mathrm{CH}_{4}$ concentrations and assumed changes in background levels of $\mathrm{OH}$, the primary reactant with $\mathrm{CH}_{4}$. (Khalil and Rasmussen, 1994), (b) Historical $\mathrm{CH}_{4}$ emissions from 1950-1995 based on estimates of population, agricultural indicators, energy use, and other drivers for $\mathrm{CH}_{4}$ emissions (Hayhoe, 1997).

the doubling of global $\mathrm{CH}_{4}$ concentrations since preindustrial times, makes it one of the most important greenhouse gases. $\mathrm{CH}_{4}$ is responsible for almost $20 \%$ of the increase in radiative forcing on climate due to anthropogenic greenhouse gas emissions since preindustrial times (IPCC, 1996a).

In contrast to the numerous sources of $\mathrm{CH}_{4}$, there are only one major and two minor sinks for tropospheric $\mathrm{CH}_{4}$. Reaction with the hydroxyl radical $(\mathrm{OH})$ is responsible for the removal of approximately $490 \mathrm{TgCH}_{4} /$ year $(88 \%$ of the total sink). The remainder of the $\mathrm{CH}_{4}$ is removed through reactions with soil, $30 \mathrm{TgCH}_{4} /$ year $(\sim 5 \%)$, or transport to the stratosphere, $40 \mathrm{TgCH}_{4} /$ year $(\sim 7 \%)$.

The current globally averaged atmospheric concentration of $\mathrm{CH}_{4}$ is about 1.73 ppmv [Fig. 9(a); Dlugokencky et al., 1998]. Continuous monitoring of $\mathrm{CH}_{4}$ trends in ambient air from 1979 to 1989 indicates that concentrations had been increasing at an average of about 16 ppbv $^{5}$ or $1 \%$ per year. In the late 1980 s, rates of increase fell to about 10 ppbv/year (Steele et al., 1992;

\footnotetext{
${ }^{5}$ ppbv $=$ Parts per billion $\left(10^{9}\right)$ by volume
}
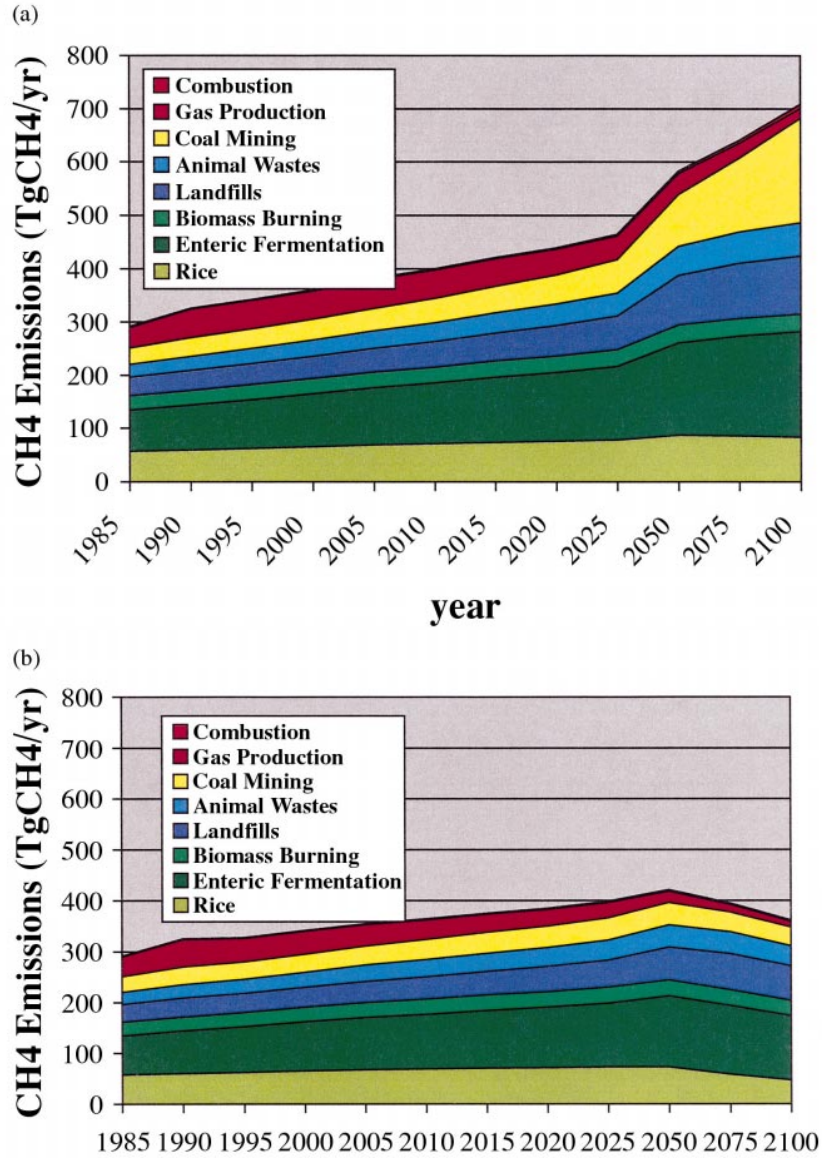

\section{year}

Fig. 8. Projections of annual anthropogenic $\mathrm{CH}_{4}$ emissions from agriculture, waste, and fossil fuel use for IPCC scenarios IS92a and c (IPCC, 1992).

Khalil and Rasmussen, 1993), declining even further in the early 1990 s before stopping entirely at some locations in 1992 [Fig. 9(b); Dlugokencky et al., 1998]. In 1994, global $\mathrm{CH}_{4}$ growth rates recovered to about $8 \mathrm{ppbv} /$ year. A number of theories suggesting reductions in emissions from anthropogenic or natural sources or a slowing in the rate of $\mathrm{CH}_{4}$ removal have been proposed (e.g. Bekki et al., 1994; Dlugokencky et al., 1994, 1996; Hogan and Harriss, 1994). The sharp increase followed by a dip in the early 1990s appear to be connected to changes in atmospheric chemistry and temperature induced by the Pinatubo eruption (Dlugokencky et al., 1996). However, the cause of the longer-term global decline in $\mathrm{CH}_{4}$ growth is still not well understood.

\section{3. $\mathrm{N}_{2} \mathrm{O}$}

$\mathrm{N}_{2} \mathrm{O}$ is a greenhouse gas that on a molecule-to-molecule basis is 200 times more efficient than $\mathrm{CO}_{2}$ in absorbing infrared radiation. Also, through reactions with excited oxygen atoms, $\mathrm{N}_{2} \mathrm{O}$ is the primary source of the nitrogen oxides that account for a significant 

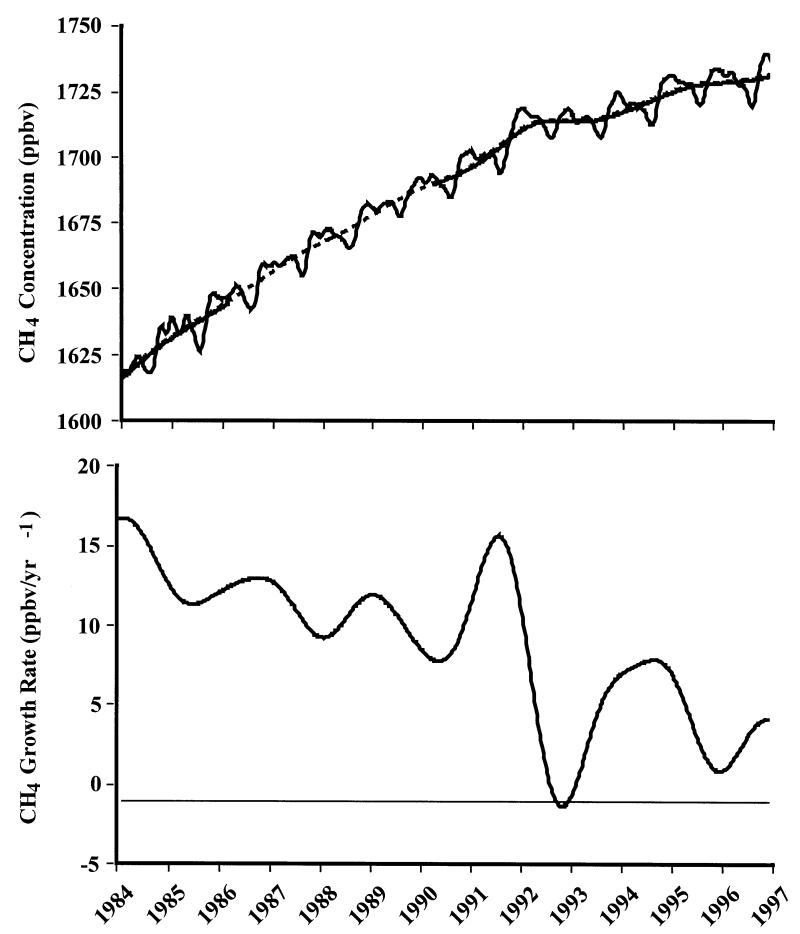

Fig. 9. (a) Globally averaged atmospheric $\mathrm{CH}_{4}$ concentrations (ppbv) derived from NOAA Climate Monitoring Diagnostic Laboratory airsampling sites (Dlugokencky et al., 1998). The solid line is a deseasonalized trend curve fitted to the data. The dashed-line is a model (that accounts for $\mathrm{CH}_{4}$ emissions and loss in the atmosphere) estimated calculated trend that fit to the globally average values. (b) Atmospheric $\mathrm{CH}_{4}$ instantaneous growth rate (ppbv/year) which is the derivative with respect to the trend curve shown in above panel.

fraction of the natural destruction of ozone in the stratosphere. $\mathrm{N}_{2} \mathrm{O}$ is also produced by various natural and anthropogenic sources, most of which are not well quantified. Based on estimates by IPCC (1995), mean emissions from natural sources include: oceans, $3 \mathrm{TgN} /$ year'; tropical soils (wet forests, dry savannas), $4 \mathrm{TgN} /$ year; and temperate soils (forests, grasslands), $2 \mathrm{TgN} /$ year. Anthropogenic sources include fertilized cultivated soils, 3.5 $\mathrm{TgN} /$ year; biomass burning, $0.5 \mathrm{TgN} /$ year; industrial sources, $1.3 \mathrm{TgN} /$ year; and cattle and feed lots, 0.4 $\mathrm{TgN} /$ year.

The major sink for $\mathrm{N}_{2} \mathrm{O}$ is photodissociation by sunlight in the stratosphere. The current best estimate for stratospheric removal, based on stratospheric chemistry modeling, is $12.5 \mathrm{TgN} /$ year (IPCC, 1995). There is some evidence that $\mathrm{N}_{2} \mathrm{O}$ is consumed by certain soils, but there are not enough data to make a reasonable global estimate of this sink.

Atmospheric measurements and ice core data indicate a continuous increase in $\mathrm{N}_{2} \mathrm{O}$ from a pre-industrial concentration of about 275 ppbv. In 1990, the mean atmospheric concentration of $\mathrm{N}_{2} \mathrm{O}$ was about $311 \mathrm{ppbv}$ (IPCC, 1996a), with a current growth rate of $0.2-0.3 \%$

\footnotetext{
${ }^{6} \mathrm{TgN}=$ teragrams of nitrogen $=10^{12}$ grams of nitrogen.
}

per year (Khalil and Rasmussen, 1992). Large uncertainties associated with the numerous small sources that make up the $\mathrm{N}_{2} \mathrm{O}$ budget make it difficult to fully explain its increase in concentration.

\subsection{Halocarbons}

Halocarbons are greenhouse gases that can contribute to climate change as well as being largely responsible for stratospheric ozone loss over recent decades. Because of their dual impact, they are of particular concern to the environment. Amongst the most potent halocarbons in the current atmosphere are the CFCs CFC-11 $\left(\mathrm{CFCl}_{3}\right)$ and CFC-12 $\left(\mathrm{CF}_{2} \mathrm{Cl}_{2}\right)$. One molecule of CFC-11 or -12 in the atmosphere is respectively, 12,400 and 15,800 times more effective a greenhouse gas than one molecule of $\mathrm{CO}_{2}$ (IPCC, 1990). With the exception of the naturally-occurring portions of $\mathrm{CH}_{3} \mathrm{Cl}$ and $\mathrm{CH}_{3} \mathrm{Br}$ emissions, all the halocarbons in the atmosphere are man-made. Their inertness and long lifetimes have made them attractive chemicals for use as propellants, refrigerants, fire retardants, and other industrial applications.

Halocarbons containing chlorine and/or bromine are of particular concern with regard to destruction of stratospheric ozone. Bromine and chlorine effectively catalyze ozone destruction cycles (WMO, 1995, 1998). These halocarbons, plus others such as the perfluorocarbons (PFCs), and the hydrofluorocarbons (HFCs) that contain fluorine instead of chlorine, also have the potential to affect climate change since these species characteristically have strong infrared absorption features in the radiation 'window' region of the atmosphere.

Measurements of CFCs and other compounds by the NOAA Climate Monitory and Diagnostic Laboratory laboratory at sites throughout the world are shown in Fig. 10. CFC-11 and -12 have the largest atmospheric concentrations, at 0.26 and 0.53 ppbv, respectively. The tropospheric concentrations of both of these gases were increasing at about $4 \%$ per year in the early 1990 s, but have now slowed appreciably. The concentrations of CFC-11 and several other controlled halocarbons have already started to decline (WMO, 1998). The use of these compounds has diminished greatly, with all but essential applications being banned by the beginning of 1996. The atmospheric concentrations of several other halocarbons have, until recently, been growing at even a faster rate than CFC-11 and -12. For example, the concentration of CFC-113 $\left(\mathrm{C}_{2} \mathrm{~F}_{3} \mathrm{Cl}_{3}\right)$, was increasing about $10 \%$ per year in the early 1990 s but has also slowed greatly, with a current concentration of about 0.08 ppbv. Abundances of the shorter-lived controlled cxompound methyl chloroform, $\mathrm{CH}_{3} \mathrm{CCl}_{3}$, have declined appreciably. $\mathrm{HCFC}-22\left(\mathrm{CHF}_{2} \mathrm{Cl}\right)$, a refrigerant often found in home air conditioners, has gained increased use as a replacement for CFCs and its concentration has been increasing at about 5-6\% per year since 1995 (Montzka et al., 1993; IPCC, 1995; 


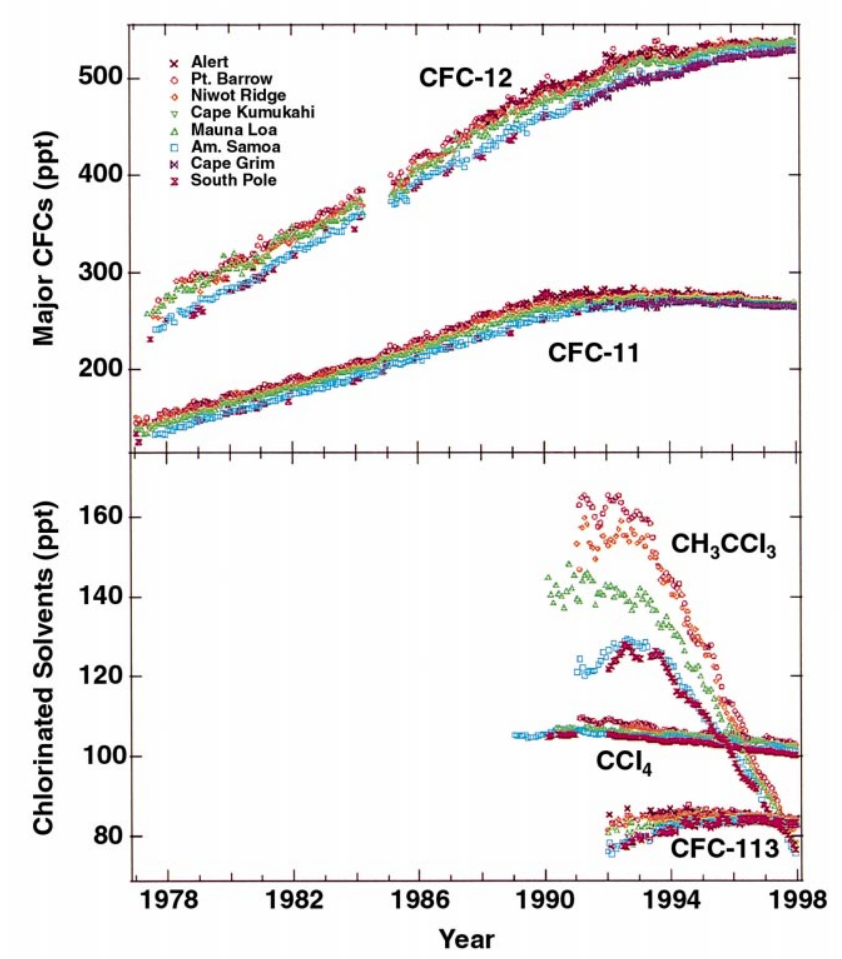

Fig. 10. Changes in measured CFC concentrations over time, showing a sharp rise over the last few decades, and the beginning of a recent decline. Based on measurements from NOAA Climate Monitoring and Diagnostics Laboratory (Elkins, private communication, 1998; updated from Elkins et al, 1993, and Montzka et al., 1996).

WMO, 1998). The measured concentrations of several other replacements are also increasing.

All of the fully halogenated CFCs have long atmospheric lifetimes. The lifetime of CFC-11 is about 50 years, while the lifetime of CFC-12 is about 102 years. The atmospheric lifetimes of HCFCs, HFCs, and other halocarbons containing hydrogen tend to be much shorter than the CFCs. Because of these shorter lifetimes, less of the replacement compounds containing chlorine and bromine reach the stratosphere and they have less effect on ozone than the CFCs.

Bromine is more effective at destroying ozone than chlorine. Therefore, early rapid increases in atmospheric concentrations of bromine-containing halons, most notably $\mathrm{Ha}-1301$ (CF3Br) and $\mathrm{Ha}-1211\left(\mathrm{CF}_{2} \mathrm{ClBr}\right)$, have caused concern. Despite their control under the Montreal Protocol, the concentrations of several halons, including $\mathrm{CBrClF}_{2}(\mathrm{H}-1211)$ and $\mathrm{CBrF}_{3}(\mathrm{H}-1301)$, continue to increase. Primary destruction of these compounds occurs through photolysis, resulting in long atmospheric lifetimes (65 years for Ha-1301; 20 years for Ha-1211). These compounds, however, currently have small atmospheric concentrations, about $4 \mathrm{pptv}^{7}$ or less (Butler et al., 1992; IPCC, 1995, 1996a; WMO, 1998). Hence, their contribution to absorption of infrared radiation is considered minimal.

\footnotetext{
${ }^{7}$ pptv $=$ Parts per trillion $\left(10^{12}\right)$ by volume.
}

\subsection{Projection of future concentrations}

Projections of future greenhouse gas concentrations depend, among other things, on assumptions made about the factors governing future emissions. Stabilization of atmospheric greenhouse gas concentrations is often used as a target against which to evaluate the possibility of emission reductions, and estimate future concentrations.

Since our current understanding of the relationship between observed increases in atmospheric $\mathrm{CO}_{2}$ and past fossil fuel emissions is imperfect, our ability to project future $\mathrm{CO}_{2}$ concentrations is also in doubt. However, all evidence indicates that fossil fuel use can raise $\mathrm{CO}_{2}$ levels to twice the pre-industrial concentration over the next 50 years. Drastic emissions reductions would therefore be required in order to hold $\mathrm{CO}_{2}$ constant (Emanuel et al., 1985; IPCC, 1990, 1995, 1996a). Current models of carbon storage and exchange suggest that for atmospheric concentrations to stabilize below 750 ppmv, human-related emissions must eventually decline relative to today's levels. Stabilization at 450 ppmv by 2100 would require reductions to about a third of today's levels. All of the models used in recent IPCC (1995, 1996a) studies indicate that holding emissions constant at 1990 levels would still result in increasing concentrations of atmospheric $\mathrm{CO}_{2}$ that would reach 500 ppmv around 2100 .

For $\mathrm{CH}_{4}$, a 15-20 percent reduction in emissions would be required to stabilize atmospheric $\mathrm{CH}_{4}$ concentrations at present levels. It is difficult to project future emissions of $\mathrm{N}_{2} \mathrm{O}$ when anthropogenic and natural sources are so uncertain. However, it is estimated that a $70-80 \%$ reduction in $\mathrm{N}_{2} \mathrm{O}$ emissions would be necessary to stabilize concentrations at present day levels because of its long atmospheric lifetime.

Six scenarios for future emissions of greenhouse gases (IS92a-f) have been developed by IPCC (1992) that include a wide range of assumptions regarding future economic, demographic and policy factors. Scenario IS92a assumes moderate population and economic growth, similar to an earlier scenario for "Business as Usual" developed by IPCC (1990). Emissions for 11 greenhouse gases used in this scenario are given in Table 3(a), and the carbon emissions corresponding to the IS92a scenario are given in Fig. 4(a). An alternate "low emissions" scenario, IS92c, is outlined in Table 3(b), with carbon emissions shown in Fig. 4(c). IS92c assumes an initial population growth followed by a decline in the middle of the next century, low economic growth, and severe constraints on fossil fuel supplies and use. IS92c would not be expected without major controls on $\mathrm{CO}_{2}$ emissions. The treatment of CFCs and other halocarbons in these scenarios is modified in IPCC (1996a), in order to more appropriately account for the effects of the latest amendments to the Montreal Protocol. 
Table 3

Current and projected annual greenhouse gas emission estimates for the scenarios (a) IS92a and (b) IS92c of the Intergovernmental Panel on Climate Change (IPCC, 1992) with halocarbons as modified for IPCC (1996a) ${ }^{\mathrm{a}}$

\begin{tabular}{|c|c|c|c|c|c|c|c|c|}
\hline \multirow[t]{2}{*}{ Greenhouse gas } & \multicolumn{7}{|l|}{ Year } & \multirow{2}{*}{$\begin{array}{c}\text { Chang } \\
1990-\end{array}$} \\
\hline & 1990 & 2000 & 2005 & 2025 & 2050 & 2075 & 2100 & \\
\hline \multicolumn{9}{|l|}{ (a) $I S 92 a$} \\
\hline \multicolumn{9}{|l|}{$\mathrm{CO}_{2}(\mathrm{GtC})$} \\
\hline \multirow[t]{2}{*}{ Industrial land-use } & 6.1 & 7.2 & 8.0 & 11.1 & 13.7 & 16.9 & 20.4 & +230 \\
\hline & 1.3 & 1.3 & 1.2 & 1.1 & 0.8 & 0.4 & 0.1 & -108 \\
\hline $\mathrm{N}_{2} \mathrm{O}(\operatorname{Tg} \mathrm{N})$ & 12.9 & 13.8 & 14.1 & 15.8 & 16.6 & 16.7 & 17.0 & +32 \\
\hline $\mathrm{CH}_{4}(\mathrm{Tg})$ & 506 & 545 & 568 & 659 & 785 & 845 & 917 & +61 \\
\hline CFC-11(kt) & 250 & 25 & 2 & 0 & 0 & 0 & 0 & -100 \\
\hline CFC-12 (kt) & 330 & 30 & 2 & 0 & 0 & 0 & 0 & -100 \\
\hline CFC-113(kt) & 132 & 13 & 1 & 0 & 0 & 0 & 0 & -100 \\
\hline CFC-114 (kt) & 6 & 1 & 0 & 0 & 0 & 0 & 0 & -100 \\
\hline CFC-115 (kt) & 13 & 1 & 0 & 0 & 0 & 0 & 0 & -100 \\
\hline $\mathrm{CCl}_{4}(\mathrm{kt})$ & 80 & 8 & 0 & 0 & 0 & 0 & 0 & -100 \\
\hline $\mathrm{CH}_{3} \mathrm{CCl}_{3}(\mathrm{kt})$ & 520 & 54 & 6 & 0 & 0 & 0 & 0 & -100 \\
\hline HCFC-22 (kt) & 319 & 484 & 383 & 3 & 0 & 0 & 0 & -100 \\
\hline
\end{tabular}

(b) $I S 92 c$

$\mathrm{CO}_{2}(\mathrm{Gt} \mathrm{C})$

Industrial land-use

$\mathrm{N}_{2} \mathrm{O}(\mathrm{Tg} \mathrm{N})$

$\mathrm{CH}_{4}(\mathrm{Tg})$

CFC-11(kt)

CFC-12 (kt)

CFC-113(kt)

CFC-114 (kt)

CFC-115 (kt)

$\mathrm{CCl}_{4}(\mathrm{kt})$

$\mathrm{CH}_{3} \mathrm{CCl}_{3}(\mathrm{kt})$

HCFC-22 (kt)

$\begin{array}{rccc}6.1 & 6.2 & 6.5 & 7.1 \\ 12.9 & 13.6 & 13.8 & 15.0 \\ 506.0 & 526.0 & 540.0 & 589.0 \\ 250 & 25 & 2 & 0 \\ 330 & 30 & 2 & 0 \\ 132 & 13 & 1 & 0 \\ 6 & 1 & 0 & 0 \\ 13 & 1 & 0 & 0 \\ 80 & 8 & 0 & 0 \\ 520 & 54 & 6 & 0 \\ 319 & 484 & 383 & 3\end{array}$

$\begin{array}{cc}6.8 & 5.4 \\ 15.0 & 14.2 \\ 613.0 & 584.0 \\ 0 & 0 \\ 0 & 0 \\ 0 & 0 \\ 0 & 0 \\ 0 & 0 \\ 0 & 0 \\ 0 & 0 \\ 0 & 0\end{array}$

$\begin{array}{rr}4.8 & -115 \\ 13.0 & +6 \\ 546.0 & +8 \\ 0 & -100 \\ 0 & -100 \\ 0 & -100 \\ 0 & -100 \\ 0 & -100 \\ 0 & -100 \\ 0 & -100 \\ 0 & -100\end{array}$

a Only human related emissions are included for most gases, with $\mathrm{N}_{2} \mathrm{O}$ and $\mathrm{CH}_{4}$ also including natural emissions, assumed to be constant at 8 Tg $\mathrm{N}$ per year for $\mathrm{N}_{2} \mathrm{O}$ and $155 \mathrm{Tg}$ per year for $\mathrm{CH}_{4}$.

The calculation of future concentrations of greenhouse gases requires modeling the processes that transform and remove the different gases from the atmosphere. Here, future concentrations of $\mathrm{CO}_{2}$ are calculated with the carbon cycle model of Jain et al. (1996), which takes into account exchanges of $\mathrm{CO}_{2}$ between the atmosphere, the oceans, and the terrestrial biosphere. Concentrations of $\mathrm{CH}_{4}, \mathrm{~N}_{2} \mathrm{O}, \mathrm{CFC}-11$ and 12 and HCFC-22 are calculated using the Integrated Science Assessment Model (ISAM; Jain et al., 1994) that simulates the removal of these chemically active gases.

When these models are used to calculate concentrations resulting from the emissions given in Table 3 , it can be seen that both emission scenarios, IS92a and IS92c, imply increases in concentrations of $\mathrm{CO}_{2}, \mathrm{CH}_{4}$, and $\mathrm{N}_{2} \mathrm{O}$ from 1990 to 2100 and beyond. Depending on the scenario, $\mathrm{CO}_{2}$ concentration increases from 38 to $100 \%, \mathrm{CH}_{4}$ from 12 to $68 \%$, and $\mathrm{N}_{2} \mathrm{O}$ from 7 to $15 \%$. On the other hand, the concentration trends of CFCs and HCFCs decline, since complete phase-out of emissions is assumed. Stabilization of these greenhouse gas concentrations to current levels or below would require much greater emission reductions than those required to follow the "low emissions" scenario IS92c as opposed to the "Business as Usual" scenario IS92a described above.

\section{Human-related effects on ozone}

\subsection{Ozone in the global atmosphere}

Ozone $\left(\mathrm{O}_{3}\right)$, is composed of three oxygen atoms and is a gas at atmospheric pressures and temperatures. Most of the ozone in the atmosphere - about $90 \%$ - is in the stratosphere, the layer of the atmosphere about 10-50 $\mathrm{km}$ above the Earth's surface. The remaining ozone is in the troposphere, the lower region of the atmosphere extending from the Earth's surface up to roughly $10 \mathrm{~km}$ at midlatitudes and $16 \mathrm{~km}$ in the tropics. Fig. 11 shows a typical integrated column of ozone, referred to as the 'total ozone column', as a function of latitude and season based on the satellite observations from the Total Ozone Mapping Spectrophotometer (TOMS) instrument (McPeters et al., 1996). Despite the primary production of ozone occurring in the tropics and the mid-latitudes, 


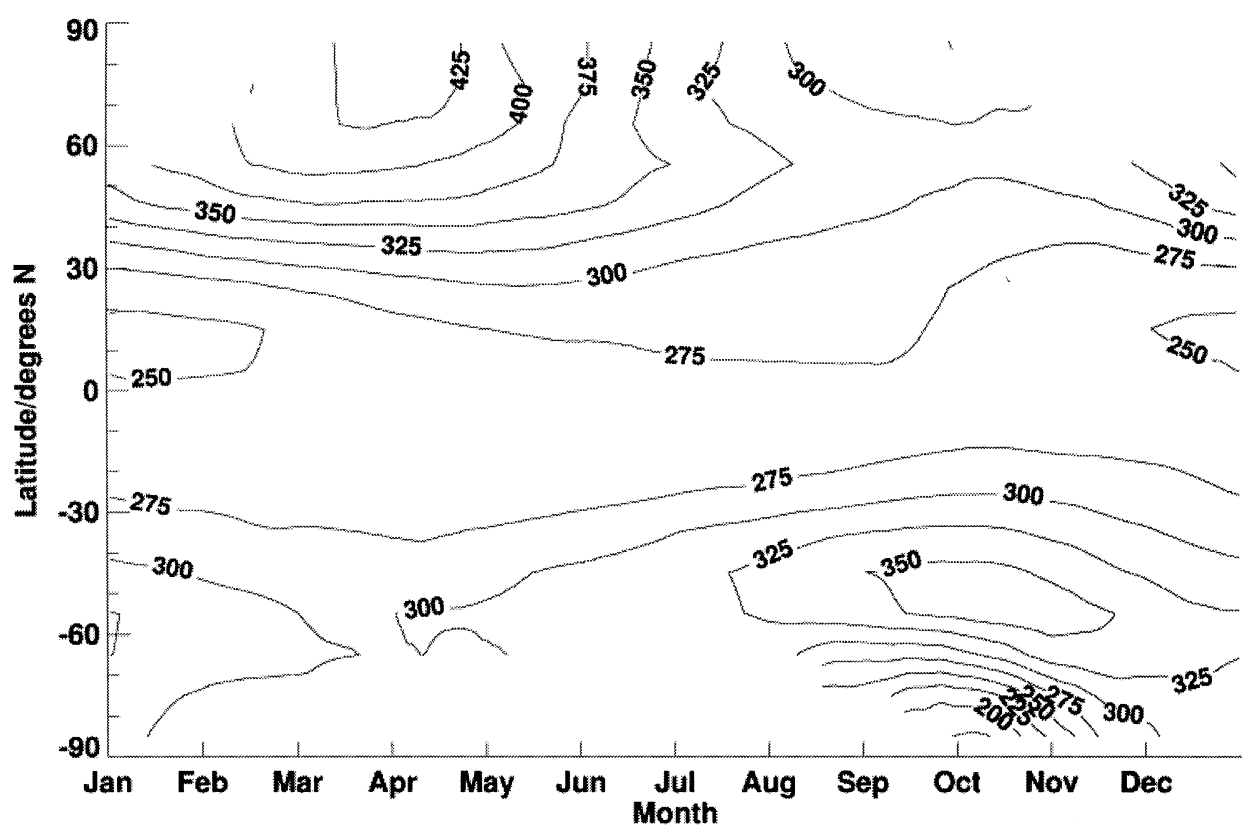

Fig. 11. Integrated column of ozone, referred to as the total ozone column, as a function of latitude and season based on Total Ozone Mapping Spectrophotometer (TOMS) satellite observations (McPeters et al., 1996).

the largest amounts of ozone are found at high latitudes as a result of the pole-ward transport of ozone by atmospheric dynamical processes.

While the ozone in the troposphere and stratosphere is chemically identical, it has very different effects on life on the Earth depending on its location. Stratospheric ozone plays a beneficial role by absorbing solar ultraviolet radiation (UV-B), preventing biologically harmful levels of UV radiation from reaching the Earth's surface (UNEP, 1989, 1991; SCOPE, 1992). Concerns about increased UV-B from ozone loss has been the driver for policy actions to protect the ozone layer.

Ozone is also a greenhouse gas, with a large infrared absorption band in the atmospheric window, at $9.6 \mu \mathrm{m}$. It is the balance between the solar and infrared radiative processes that determines the net effect of ozone on climate (IPCC, 1990, 1992, 1995, 1996a; Lacis et al., 1990). Temperature increases with altitude in the stratosphere, a phenomenon that is explained by the absorption of solar radiation by ozone. Increases in stratospheric ozone above $30 \mathrm{~km}$ tend to decrease the Earth's surface temperature as a result of the increased absorption of solar radiation, effectively decreasing the solar energy that would otherwise warm the Earth's surface. Below $30 \mathrm{~km}$, increases in ozone tend to increase the surface temperature, and the infrared greenhouse effect dominates in this region.

Closer to the Earth's surface, ozone displays its destructive side. Ozone is a strong oxidizer. Hence, direct exposure to high levels of ozone has toxic effects on human health and plants (SCOPE, 1992). Although ozone is a major component of photochemical smog in urban areas, this ozone is generally not thought to be a significant contributor to the global ozone budget. However, balloon measurements suggest that tropospheric ozone at the global scale has been increasing (WMO, 1995, 1998).

\subsection{Stratospheric ozone trends}

Concentrations of ozone in the stratosphere are determined by chemical production and destruction processes in combination with transport processes. Production of ozone in the stratosphere results primarily from photodissociation of oxygen molecules. The destruction of ozone occurs mainly through catalytic reactions with other gases, such as chlorine and bromine. The total amount of ozone in the stratosphere will remain fairly constant (relative to well-recognized seasonal variations) as long as there is no change in the destruction rate and the transport of ozone out of the stratosphere. However, increasing inputs of chlorine and bromine into the stratosphere over the past few decades have changed this balance.

Measurements of ozone by satellite and ground-based measurements over the last several decades indicate that stratospheric ozone levels have decreased significantly (e.g. WMO, 1991, 1995, 1998; SPARC, 1998). Atmospheric ozone has decreased globally by more than $5 \%$ since 1970 (WMO, 1995, 1998). Fig. 12, based on WMO (1998) and SPARC (1998), shows satellite and groundbased measurements of the change in ozone from $60^{\circ} \mathrm{S}$ to $60^{\circ} \mathrm{N}$ latitudes. Satellite measurements began in late 1978, while a reasonably representative global network of ground-based stations has been in operation since the late 1960s. Seasonal variations and the effects of the 

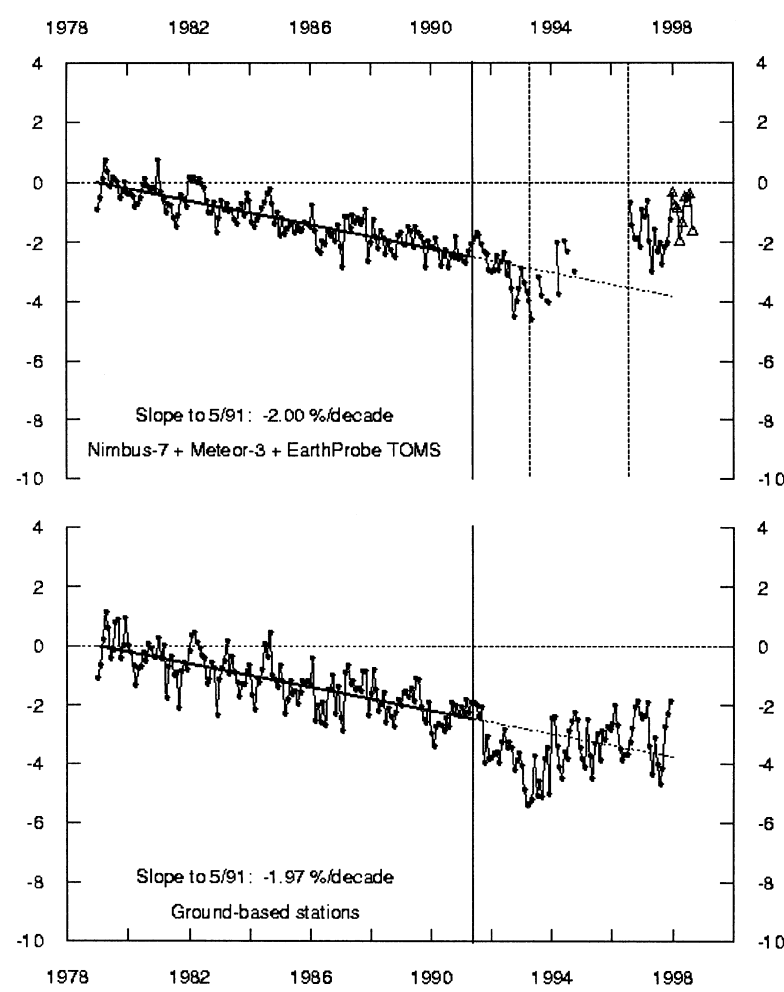

Fig. 12. Deviations in total ozone with time relative to January 1979 from various ground-based (bottom panel) and satellite measurements (top two panels). The data is area-weighted over $60^{\circ}$ south to $60^{\circ}$ north. Based on WMO (1998).

variations in the solar flux due to 11-year solar cycle, which would produce about a $1.2-1.5 \%$ variation from solar minimum to solar maximum (Wuebbles et al., 1991), have been removed from the data shown. Significant decreases in total ozone are found in both the Northern and Southern Hemisphere at the middle and high latitudes, with no significant change in the tropics. Much larger decreases in total ozone are found at latitudes greater than 60 degrees, particularly in the Southern Hemisphere. Fig. 13 shows the seasonal variations of the trends in total ozone since 1979 as a function of latitude. Surface measurements indicate that the total ozone column at midlatitudes in the Northern Hemisphere has decreased by $1.3 \%$ per decade in the summer months and $2.7 \%$ per decade in the winter months since 1969 (WMO, 1995, 1998).

Satellite and ozonesonde or balloon data sets indicate that ozone is particularly decreasing in the lower stratosphere, accounting for a major fraction of the trend in total ozone, although there is also significant ozone destruction occurring in the upper stratosphere (WMO, 1995, 1998). Fig. 14 shows the annually averaged change in ozone with latitude and altitude for 1979 through 1996 from the SAGE satellite observations (based on WMO, 1998). Large percentage decreases in ozone, approaching $1 \%$ per year, are found in the upper stratosphere. However, there is much less ozone in this region than in the lower stratosphere, where the smaller percentage changes actually imply larger numbers of molecules destroyed.

Beginning in the late 1970s, a special phenomenon began to occur in the springtime over Antarctica, referred to as the Antarctic ozone 'hole'. A large decrease in total ozone, now over $60 \%$ relative to pre-hole levels, has been observed in the springtime (September to November) over Antarctica. Farman et al. (1985) first documented this rapid springtime decrease in Antarctic ozone over their British Antarctic Survey (BAS) station at Halley Bay, Antarctica. This attracted the attention of the scientific community, who soon found that decreases in the total ozone column were greater than $50 \%$ compared with historical values observed by both ground-based and satellite techniques. Measurements made in 1987 indicated that more than $95 \%$ of the ozone over Antarctica at altitudes from 13 to $22 \mathrm{~km}$ had disappeared during September and October. Since 1992, the Antarctic ozone holes have been the biggest (in areal extent) and the deepest (in terms of minimum amounts of ozone overhead), with ozone being locally depleted by more than $99 \%$ between about $14-19 \mathrm{~km}$ in October (WMO, 1995, 1998).

\subsection{Causes and consequences of stratospheric ozone depletion}

The connection between potential environmental effects and man-made CFCs was first pointed out by Molina and Rowland (1974), when they suggested that chlorine from these compounds could destroy stratospheric ozone. Research findings since then have continued to support the effect of these compounds on the global distribution of ozone. In addition, it is recognized that other gases containing chlorine and bromine, which is even more reactive with ozone than chlorine, are also affecting ozone. To a lesser extent, increasing concentrations of other gases like $\mathrm{CO}_{2}, \mathrm{CH}_{4}$, and $\mathrm{N}_{2} \mathrm{O}$, are also involved in chemical reactions that are affecting stratospheric ozone.

The inverse relationship between changes in ozone and UV-B radiation is well established by both theoretical analyses and observations (WMO, 1998). Fig. 15 shows this inverse relationship in measurements from several sites (Madronich et al., 1999). A number of studies have shown that the corresponding increase in UV$\mathrm{B}$ at the ground resulting from ozone depletion can lead to increased incidences of skin cancers, cataracts, and other effects on humans and animals.

The recognition of the harmful effect of chlorine and bromine on ozone spawned international action to restrict the production and use of CFCs and halons and protect stratospheric ozone. These included the 1987 Montreal Protocol on Substances that Deplete the Ozone Layer (UN, 1987), the subsequent 1990 London Amendment 
(a) - Dec-Jan-Feb

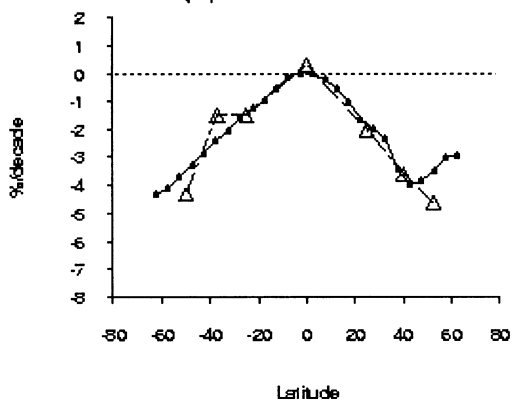

(c) - Jun-Jul-Aug

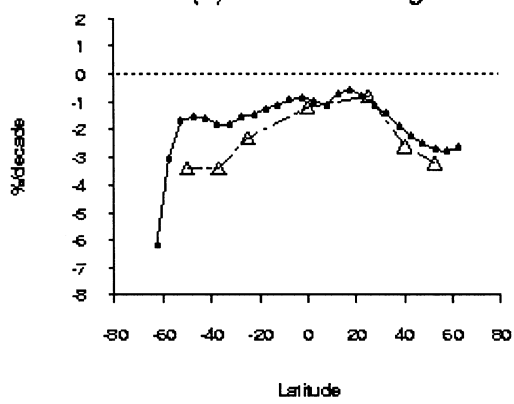

(e) - Year Round

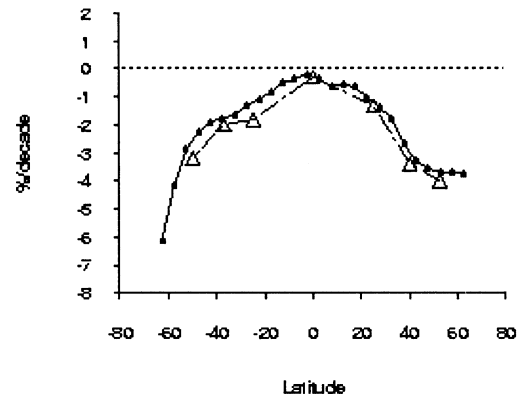

(b) - Mar-Apr-May

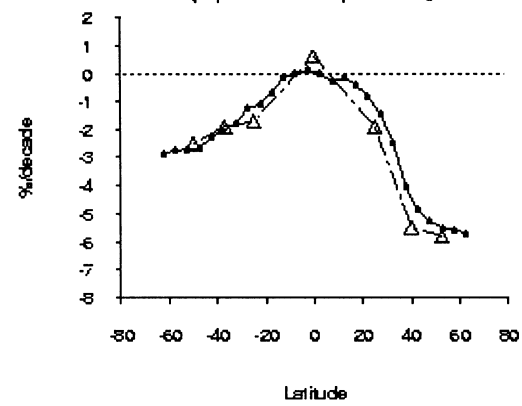

(d) - Sep-Oct-Nov

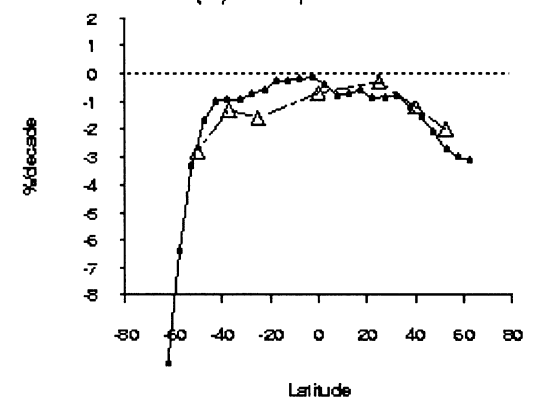

$\Delta-A-A$ Ground-based

Fig. 13. Change in total ozone with latitude and season from January 1979 to January 1998 for satellite Total Ozone Mapping Spectrophotometer (TOMS) measurements, and to May 1997 for ground-based Dobson measurements. Based on WMO (1998).

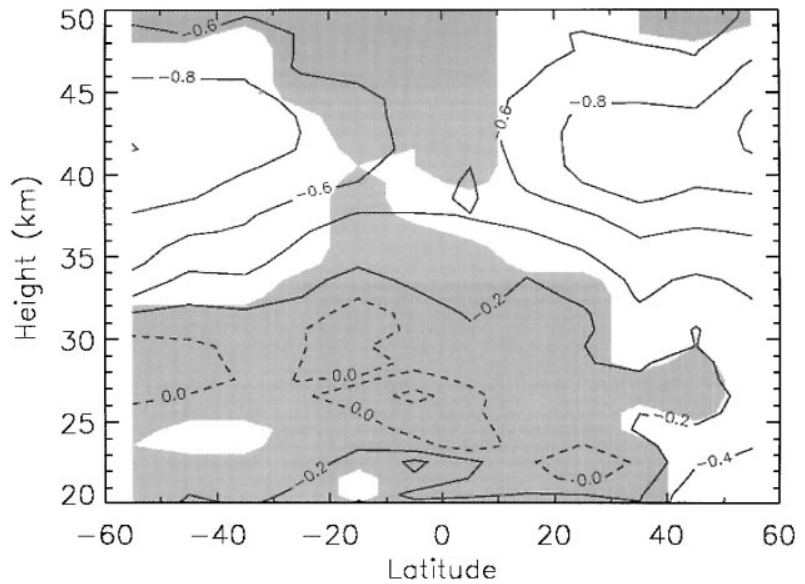

Fig. 14. Annually-averaged change in ozone with latitude and altitude from SAGE satellite observations (1979-1996). The shaded areas indicate where the trends do not differ from zero within the $95 \%$ confidence limits. Based on WMO (1998).

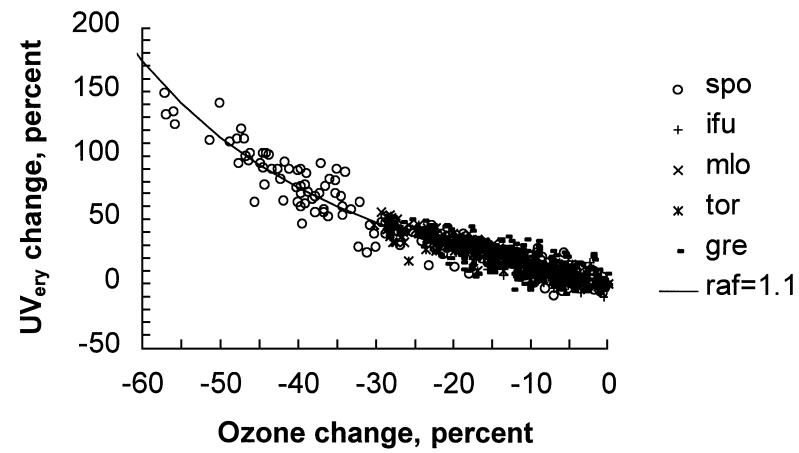

Fig. 15. Dependence of erythemal ultraviolet (UV) radiation at the Earth's surface on atmospheric ozone, measured on cloud-free days at various locations, at fixed solar zenith angles. Legend: South Pole (Booth and Madronich, 1994); Mauna Loa, Hawaii (Bodhaine et al., 1997); Lauder, New Zealand (McKenzie et al., 1997); Thessaloniki, Greece (updated from Zerefos et al., 1997); Garmisch, Germany (Mayer et al., 1997); and Toronto, Canada (updated from Fioletov and Evans, 1997). Solid curve shows model prediction with a power rule using RAF $=1.10$. Based on Madronich et al. (1999). 
(UNEP, 1990), the 1992 Copenhagen Amendment (UNEP, 1992) and the 1997 Montreal Amendment. These agreements initially called for reduction of CFC consumption in developed countries. A November 1992 meeting of the United Nations Environment Program held in Copenhagen resulted in substantial modifications to the protocol because of large observed decrease in ozone, and called for the phase-out of CFCs, carbon tetrachloride $\left(\mathrm{CCl}_{4}\right)$, and methyl chloroform $\left(\mathrm{CH}_{3} \mathrm{CCl}_{3}\right)$ by 1996 in developed countries. As part of this, the USA, through the Clean Air Act, has eliminated production and import of these chemicals. Production of these compounds is to be totally phased out in developing countries by 2006, while production of halons in developed countries was stopped in 1994. Human-related production and emissions of methyl bromide are not to increase after 1994 in developed countries, and should slowly decline with total elimination by 2005 .

\subsection{Projected trends in ozone}

Projected changes in globally averaged total ozone for several assumptions about future emissions of CFCs, halons and their replacements are shown in Fig. 16 (based on Wuebbles et al., 1999). With the original Montreal Protocol provisions, the rate of ozone reduction would be $15 \%$ relative to 1980 levels. It is important to note that only under the London and Copenhagen Amendments provisions, calling for the complete phase-out of CFCs, halons and other halocarbons, is the ozone reduction trend reversed. The largest ozone reductions are reached at about 1998. After this, ozone gradually recovers, although it is not until about 2040 (Copenhagen Amendments) and about 2050 (London Amendments) that the 1980 level is again obtained. Thus, it will be roughly the middle of the next century before the chlorine and bromine in the stratosphere return to levels corresponding to the beginning of the Antarctic ozone 'hole'. Without any control measures and assuming unfettered growth, the global mean total column ozone would have decreased about $30 \%$ by 2050, and would have continued to decrease with time.

The black line in Fig. 17 corresponds to the observed changes in ozone relative to 1980 up to the mid-1990s, and follows the changes in ozone expected if the latest version of the Montreal Protocol is adhered to. However, this line assumes that the change in ozone is only dependent on the amount of chlorine and bromine in the stratosphere, whereas recent modeling studies (WMO, 1995, 1998) are showing a strong dependence on the changes occurring in other gases and in climate. The uncertainty in the background atmosphere could affect the timing for the return to natural ozone levels, possibly increasing the time by several decades (WMO, 1998).

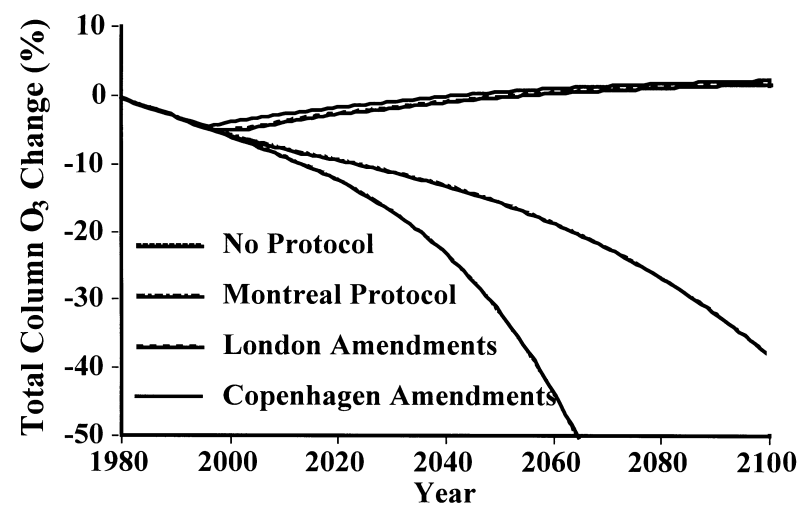

Fig. 16. Estimated total column ozone change for the No Protocol, Montreal Protocol and London Amendment and Copenhagen Amendment scenarios. Based on analyses by Wuebbles and Jain using their model for equivalent chlorine loading.

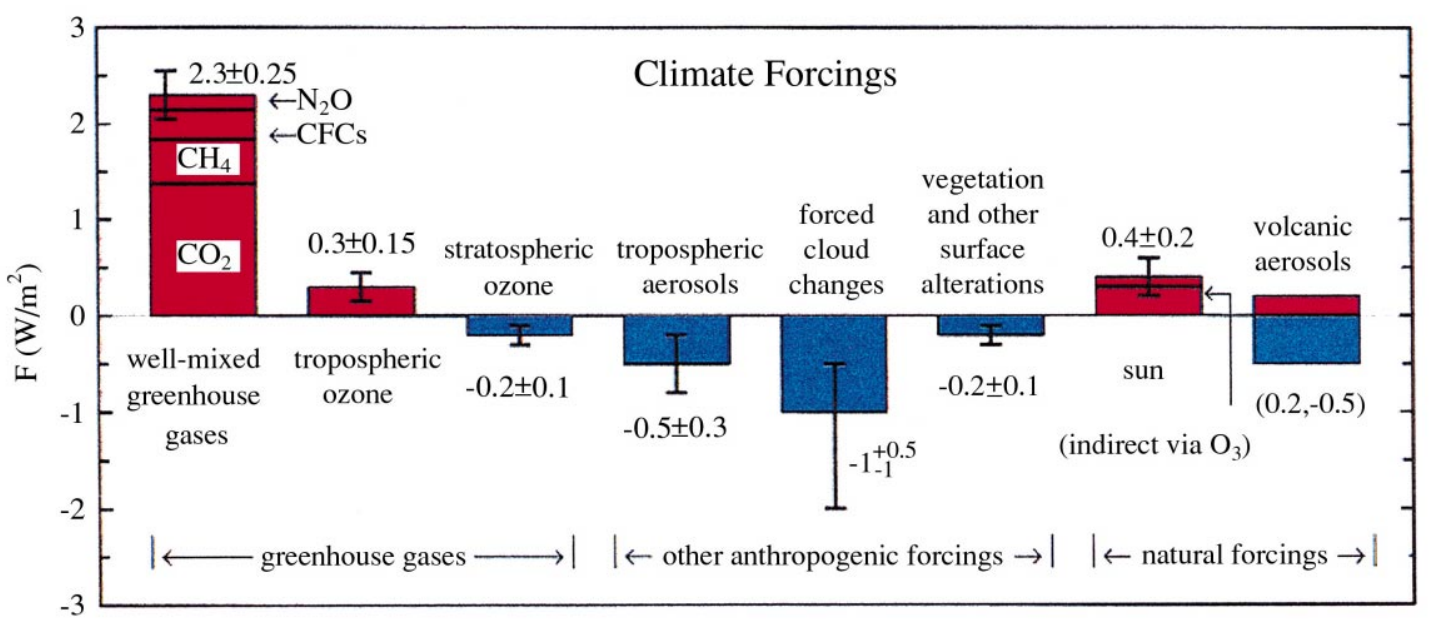

Fig. 17. Estimated globally and annually averaged anthropogenic radiative forcing $\left(\mathrm{Wm}^{-2}\right)$ due to changes in concentrations of greenhouse gases and aerosols from pre-industrial time to the present day and to natural changes in solar output from 1850 to the present day. The error bars show an estimate of uncertainty range. The subjective confidence that the actual forcing lies within this error bar is indicated by the "confidence level". (Source: Hansen, private communication). 


\section{Human-related climate change}

\subsection{Radiative forcing}

A perturbation to the atmospheric concentration of an important greenhouse gas, or the distribution of aerosols, induces a radiative forcing that can affect climate. In keeping with the definition adopted by the IPCC (1990, 1992, 1995, 1996a), radiative forcing of the surface troposphere system is defined as the change in net radiative flux at the tropopause due to a change in either solar or infrared radiation. Generally, this net flux is calculated after allowing for stratospheric temperatures to readjust to radiative equilibrium. A positive radiative forcing tends, on average, to warm the surface; a negative radiative forcing tends to cool the surface. This definition is based on earlier climate modeling studies, which indicated an approximately linear relationship between the global mean radiative forcing at the tropopause and the resulting global mean surface temperature change (e.g. Hansen et al., 1981; Ramanathan et al., 1985, 1987). However, recent studies of greenhouse gases (e.g. Hansen et al., 1997) indicate that the climatic response can be sensitive to the altitude, latitude, and nature of the forcing.

\subsubsection{Past trends in radiative forcing}

4.1.1.1. Greenhouse gases. Published analyses of the direct radiative forcing due to the changes in greenhouse gas concentrations since the late 1700 s are generally in good agreement, giving an increase in radiative forcing of about $2.1-2.6 \mathrm{Wm}^{-2}\left(2.45 \mathrm{Wm}^{-2}\right.$ in IPCC, 1995, 1996a). Of the $2.45 \mathrm{Wm}^{-2}$ change in radiative forcing from greenhouse gases over the last two centuries, approximately $0.5 \mathrm{Wm}^{-2}$ has occurred within the last decade. By far the largest effect on radiative forcing has been the increasing concentration of carbon dioxide, accounting for about $64 \%\left(1.56 \mathrm{Wm}^{-2}\right)$ of the total change in forcing. As seen in Fig. 17, the change in concentrations of $\mathrm{CH}_{4}, \mathrm{~N}_{2} \mathrm{O}$, and $\mathrm{CFCs}$ and other halocarbons provide another $0.9 \mathrm{Wm}^{-2}$.

4.1.1.2. Tropospheric ozone. Changes in tropospheric ozone above the boundary layer, which contains much of the ozone from local and regional air pollution, can also affect climate (Lacis et al., 1990). Ozone changes in this region are much more uncertain than those in the stratosphere, although calculations indicate that an increase in ozone over recent decades, as suggested by some measurements, should add to the warming effect in radiative forcing from greenhouse gases (Wang et al., 1993; Hauglustaine et al., 1994). Estimates of the change in radiative forcing since the 1700s for tropospheric ozone range from 0.2 to $0.6 \mathrm{Wm}^{-2}$ (IPCC, 1995).

4.1.1.3. Aerosols. Changes in amounts of sulfate, nitrate, and carbonaceous aerosols induced by natural and human activities have all contributed to changes in radiative forcing over the last century. The direct effect on climate from sulfate aerosols occurs primarily through the scattering of solar radiation. This scattering produces a negative radiative forcing, and has resulted in a cooling tendency on the Earth's surface that counteracts some of the warming effect from the greenhouse gases. Nitrate aerosols have a similar cooling effect, while carbonaceous aerosols have a warming effect.

Human-related aerosols appear to play a significant role in explaining the discrepancy between observed temperature changes and that expected from greenhouse gases (Santer et al., 1995; IPCC, 1996a). Aerosol cooling cannot be directly balanced against greenhouse gasinduced warming. Aerosol forcing, and hence cooling effects, occur on time scales and in spatial patterns that are very different from the warming caused by greenhouse gases (Taylor and Penner, 1994; IPCC, 1996a). Due to their short lifetime of only a few days to weeks, aerosol distributions are concentrated over areas such as the Northern Hemisphere continents that are downwind of major emitters of sulfur dioxides and other aerosol sources. Longer-lived greenhouse gases, on the other hand, are relatively well mixed, and their warming effects are expected to be more uniform.

Past estimates for the globally-averaged direct effect from changes in sulfate aerosols during the industrial period range from -0.2 to $-0.9 \mathrm{Wm}^{-2}$ (Charlson et al., 1991; Hansen et al., 1993; Kiehl and Briegleb, 1993; Taylor and Penner, 1994; IPCC, 1995). More recently, IPCC (1996a) estimates the direct effect of sulfate aerosols to be $-0.4 \mathrm{Wm}^{-2}$, with an uncertainty range of a factor of two. A new study by Hansen and others at NASA Goddard Institute for Space Studies (private communication, 1998) derived a cooling effect of $-0.5 \mathrm{Wm}^{-2}$ with an uncertainty of $0.3 \mathrm{Wm}^{-2}$. Carbonaceous aerosols and soot from fossil fuel sources and biomass burning may have contributed either a slight warming or cooling during this period (Penner et al., 1992; Andrae, 1993; Hansen et al., 1993; IPCC, 1996a).

The contribution of aerosols to cloud condensation nuclei is thought to produce an indirect cooling effect which may be twice the direct effect (IPCC, 1996a). Uncertainty regarding the magnitude of the direct effect may be large, but the uncertainty associated with indirect effects on clouds and cloud albedo is even larger. Radiative forcing from these effects may vary from zero up to $-1 \mathrm{Wm}^{-2}$ (Charlson et al., 1992), with an uncertainty range of $0-1.5 \mathrm{Wm}^{-2}$ (IPCC, 1996a).

Following a major volcanic eruption, stratospheric sulfate aerosols can also produce a large change in radiative forcing for several years. For example, the June 1991 eruption of Mt. Pinatubo in the Philippines is estimated to have resulted in an immediate maximum radiative forcing effect of $-4 \mathrm{Wm}^{-2}$, and as much as $-1 \mathrm{Wm}^{-2}$ up to 2 years after the eruption (Hansen et al., 1992). 
4.1.1.4. Solar variability. Changes in the solar energy output reaching the Earth is an important external forcing on the climate system. The Sun's output of energy is known to vary by small amounts over the 11-year sunspot cycle and can vary by larger amounts over longer time periods. In addition, slow variations in the Earth's orbit, over time scales of decades to thousands of years, have varied the amount of solar radiation reaching the Earth. These variations are thought to have significantly affected past climate, including the formation of the ice ages. IPCC (1996a) estimated top of the atmosphere forcings due to solar variability since 1850 to be about $+0.3 \mathrm{Wm}^{-2}$, with a lower limit of $+0.1 \mathrm{Wm}^{-2}$ (Foukal and Lean, 1990) and an upper limit of $+0.5 \mathrm{Wm}^{-2}$ (Nesme-Ribes et al., 1993).

4.1.1.5. Stratospheric ozone. Analyses of the radiative forcing effects from the observed decrease in stratospheric ozone have generally suggested a cooling influence on climate (WMO, 1991; IPCC, 1992; Ramaswamy et al., 1992; Schwarzkopf and Ramaswamy, 1993; Wang et al., 1993; Molnar et al., 1994). These analyses show a large dependence in the radiative forcing on the latitudinal variations and altitude dependence of the ozone loss. Global averaged change in radiative forcing due to this ozone decrease is approximately -0.1 to $-0.2 \mathrm{Wm}^{-2}$ (IPCC, 1995, 1996a).

4.1.1.6. Combined effects. Following the above discussion, the recent evaluation of the radiative forcing from all of the different sources since pre-industrial times as shown in Fig. 17 indicates that globally averaged radiative forcing on climate has increased. The exact amount is uncertain because of the difficulty in quantifying the overall effects on aerosols and ozone. Because of the hemispheric and other inhomogeneous variations in concentrations of aerosols, the overall change in radiative forcing could be much greater or much smaller at specific locations about the globe. The largest increase in radiative forcing should be expected in the Southern Hemisphere, where aerosol content has been the smallest.

\subsubsection{Projecting future changes in forcing}

Future changes in radiative forcing are quite uncertain due to uncertainties in future emissions and concentrations of greenhouse gases and aerosols. As an example of individual responses, Table 4 shows modelderived radiative forcing for changes in concentrations of several different gases. For comparison purposes, Table 4 also gives the effect on radiative forcing expected if the solar radiation were decreased by $2 \%$, which is comparable to a doubling of $\mathrm{CO}_{2}$. The resulting change in surface temperature shown in Table 4 assumes that no climatic feedback processes occur in the atmosphere. These results are based on the studies of Rind and Lacis (1993), although similar results have been found with other models (Ramanathan et al., 1987).
Fig. 18 shows the derived globally averaged radiative forcing as a function of time for scenarios IS92a and IS92c relative to the radiative forcing for the pre-industrial background atmosphere (using the model of Jain et al., 1994; also see IPCC, 1996a). The contribution from aerosols is probably the most uncertain part of future radiative forcings. The calculated increases in radiative forcing due to greenhouse gases, from the pre-industrial period to 2100 , are about $+6 \mathrm{Wm}^{-2}$ for scenario IS92a and $+4 \mathrm{Wm}^{-2}$ for scenario IS92c (Fig. 18). Both cases represent a sizable increase over the greenhouse gas forcing of $+2.45 \mathrm{Wm}-2$ from pre-industrial times to 1990, implying a significant future warming tendency. The negative forcing due to tropospheric aerosols offsets some of the positive greenhouse gas forcing in both scenarios, but it is insufficient to change the picture of

Table 4

Radiative forcing at the tropopause $(\mathrm{F})$ and derived surface temperature changes assuming no climatic feedbacks $(\Delta \mathrm{T} 0)$ for selected changes in forcing mechanisms ${ }^{\mathrm{a}}$

\begin{tabular}{|c|c|c|c|}
\hline Forcing mechanism & & $\mathrm{F}\left(\mathrm{W} \mathrm{m}^{-2}\right)$ & $\Delta \mathrm{T}_{0}(\mathrm{~K})$ \\
\hline $\mathrm{CO}_{2}$ & $\begin{array}{l}\text { Increase from } \\
300 \text { to } 600 \mathrm{ppmv}\end{array}$ & 4.35 & 1.31 \\
\hline $\mathrm{CH}_{4}$ & $\begin{array}{l}\text { Increase from } \\
1.6 \text { to } 3.2 \mathrm{ppmv}\end{array}$ & 0.52 & 0.16 \\
\hline $\mathrm{N}_{2} \mathrm{O}$ & $\begin{array}{l}\text { Increase from } \\
0.28 \text { to } 0.56 \mathrm{ppmv}\end{array}$ & 0.92 & 0.27 \\
\hline CFC-11 & $\begin{array}{l}\text { Increase from } \\
0 \text { to } 1 \mathrm{ppbv}\end{array}$ & 0.22 & 0.07 \\
\hline CFC-12 & $\begin{array}{l}\text { Increase from } \\
0 \text { to } 1 \mathrm{ppbv}\end{array}$ & 0.28 & 0.08 \\
\hline $\mathrm{O}_{3}$ & Decrease by $50 \%$ & -1.2 & -0.38 \\
\hline Solar constant & Increase by $2 \%$ & 4.58 & 1.35 \\
\hline
\end{tabular}

a Based on results of Rind and Lacis (1993). If climatic feedbacks were included, climate models suggest that temperatures would increase by a factor of $1-3$ or more (IPCC, 1990, 1992).

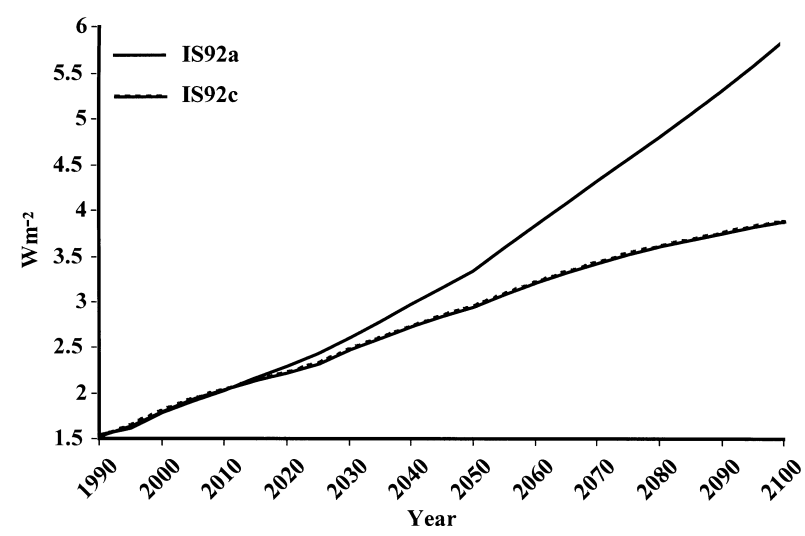

Fig. 18. Model-estimated radiative forcings derived from the IPCC emission scenarios IS92a and IS92c. The scenario curves include the radiative forcings from $\mathrm{CO}_{2}, \mathrm{CH}_{4}, \mathrm{~N}_{2} \mathrm{O}$, tropospheric $\mathrm{O}_{3}$, halocarbons (including the negative forcing effect of stratospheric ozone depletion), and aerosols. 
extensive global warming over the next century and beyond.

\subsection{The temperature record}

\subsubsection{Observed changes in the climate system and sea level during the recent past}

There is an extensive amount of evidence indicating that the Earth's climate has warmed during the past century. Foremost among this evidence are compilations of the variation in global mean sea surface temperature and in surface air temperature over land and sea. Supplementing these indicators of surface temperature change is a global network of balloon-based observations of atmospheric temperature since 1958. As well, there are several indirect or proxy indications of temperature change, including satellite observations of microwave emissions from the atmosphere, and records of the width and density of tree rings. The combination of surface-, balloon-, and satellite-based indicators provides a more complete picture than could be obtained from any given indicator alone, while proxy records from tree rings and other indicators allow the temperature record at selected locations to be extended back several centuries. Apart from temperature, changes in the extent of alpine glaciers, sea ice, seasonal snow cover, and the length of the growing season have been documented that are consistent with the evidence that the climate is warming. Less certain changes appear to have occurred in precipitation, cloudiness, and interannual temperature and rainfall variability.

\subsubsection{Surface and surface-air temperature records.}

Thermometer-based measurements of air temperature have been systematically recorded at a number of sites in Europe and North America as far back as 1760. However, the set of observing sites did not attain sufficient geographic coverage to permit a rough computation of the global average land temperature until the mid-nineteenth century. Sea surface temperatures and marine air temperatures have been systematically collected by merchant ships since the mid-nineteenth century. However, these temperature records are restricted to the routes followed by commercial ships, so there is relatively little data from large regions in the Southern Hemisphere even today. Land-based, marine air, and sea surface temperature datasets all require rather involved corrections to account for changing conditions and measurement techniques. These corrections are thoroughly discussed in Harvey (1999), where successive "corrected" time series are compared with one another. Shown in Fig. 19 is a composite of the global mean land surface air and sea surface temperature variation from 1860 to 1998, as computed by Jones and colleagues at the University of East Anglia. Jones et al. (1997a,b) have analyzed the uncertainty in the reconstructed variation

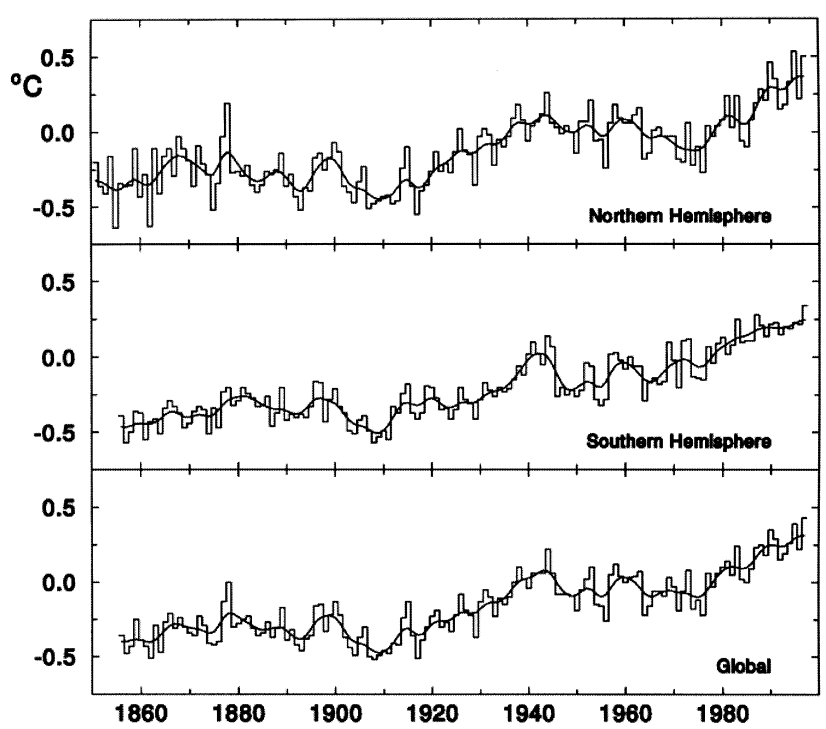

Fig. 19. Composite plot of global mean land surface air and sea surface temperature change from 1860-1997 (Source: UEA, at www.cru.uea.ac.uk).

of global mean temperature; their analysis indicates a global mean warming from 1851 to 1995 of $0.65 \pm 0.05^{\circ} \mathrm{C}$.

4.2.1.2. Balloon-based temperature records. A global network of balloon stations was established in May 1958, during International Geophysical Year. The initial network consisted of about 540 stations that reported once daily at 00:00 Greenwich mean time. Beginning in 1963, twice daily reporting, at 00:00 and 12:00 GMT, began to be important. By the 1970s the network grew to 700-800 stations with twice-daily reporting. Gaffen (1994) and Parker and Cox (1995) discuss potential discontinuities and spurious trends in the balloon temperature data due to changing instruments and operational procedures. Time series that take into account some of the known problems are compared below with satellite-based records.

4.2.1.3. Satellite-based proxy records. Microwave sensors, or 'sounding units' (MSUs), are satellite instruments that measure microwave radiation emitted by oxygen $\left(\mathrm{O}_{2}\right)$ at a wavelength of $4 \mu \mathrm{m}$. Since the atmospheric concentration of $\mathrm{O}_{2}$ is constant in space and in time, variations in the emitted radiation should be directly related to variations in the temperature of emission. Two different channels sample the radiation at slightly different frequencies, which correspond to emissions in different regions of the atmosphere: MSU channel 2 samples in the middle and lower troposphere (mainly the 850-300 mb layer), while channel 4 samples the stratosphere (mainly the 50-100 mb layer). None of the channels sample at the ground. The MSU measurements have been controversial (e.g. Jones et al., 1997b; Pielke et al., 1998; Christy et al., 1999) because some 
versions of the satellite dataset have indicated a cooling in the lower troposphere that is in contrast to the warming from the ground-based instruments. However, several errors and problems with the MSU data have recently been found (e.g. Kerr, 1998; Prabhakara et al., 1998; Wentz and Schabel, 1998). The latest analyses of MSU data, corrected for problems such as the orbital decay of the satellite, tend to show a slightly smaller warming than found at the ground (Christy, private communication, 1998, in addition to the references above).

Fig. 20 shows the variation in global mean temperature deduced for MSU-2 and -4 , along with the variation since 1964 in the balloon-based temperatures from comparable layers in the atmosphere, and in surface air temperature. This version of the MSU data for the troposphere indicates a warming of $0.09^{\circ} \mathrm{C} /$ decade (Christy et al., 1995). By comparison, Jones (1994) computed temperature trends for the $1979-1993$ period of $0.10^{\circ} \mathrm{C} /$ decade based on balloon data for the 850-300 mb layer, and $0.17^{\circ} \mathrm{C} /$ decade based on combined land-surface air and sea surface temperature data, respectively. All three trends were computed after removing the effect of an El Niño at the beginning of this time period and the effect of the Mt. Pinatubo volcanic eruption at the end. Part of the difference between MSU/balloon trends and surface-based temperature trends could be related to a real difference in the surface and mid-tropospheric temperature changes. Both the balloon and MSU data for the stratosphere indicate a cooling of $0.33^{\circ} \mathrm{C} /$ decade over the period 1979-1995 (Christy, 1995). The MSU data do not extend earlier, while the balloon-based trends in the early part of the stratospheric record are not reliable.

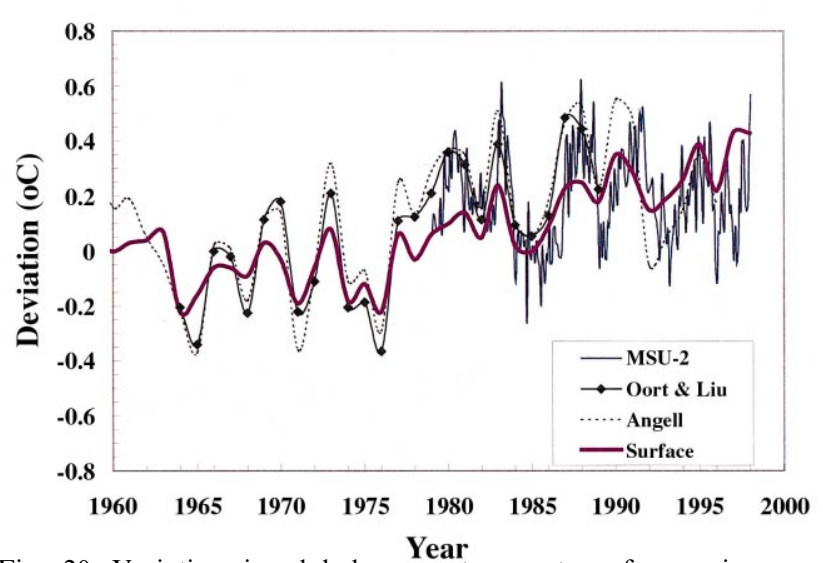

Fig. 20. Variation in global mean temperature from microwave sounding unit (MSU) satellite measurements for the lower troposphere (Channel 2), with variation in balloon-based temperatures, and surface air temperatures.

4.2.1.4. Other indications of a warming climate. The above trends and other indications of a warming climate are summarized in Table 5 , where pertinent references may also be found. All of the trends listed in Table 5 are consistent with a warming climate. This evidence, considered in total, therefore leaves no doubt that the Earth's climate has warmed during the past century.

4.2.1.5. Long proxy records. Proxy temperature indicators at a number of locations allow us to extend temperature records back several centuries (Jones, 1998; Jones et al., 1998). Mann et al. (1998) estimated the variation in Northern Hemisphere mean annual temperature since AD 1400 based on such indicators as tree ring width and density, the chemical composition and annual

Table 5

Summary of trends in observed climatic variables, based on Harvey (1999) and IPCC (1996a)

\begin{tabular}{|c|c|c|}
\hline Variable & Analysis period & Trend or change \\
\hline Surface air temperature and Sea surface temperature ${ }^{a}$ & $1851-1995$ & $0.65 \pm 0.15^{\circ} \mathrm{C}$ \\
\hline Alpine glaciers ${ }^{b}$ & Last century & Implies warming of $0.6-1.0^{\circ} \mathrm{C}$ in alpine regions \\
\hline Extent of snowcover in the Northern Hemisphere ${ }^{c}$ & 1972-1992 & $10 \%$ decrease in annual mean \\
\hline Extent of sea ice in the Northern Hemisphere ${ }^{\mathrm{d}}$ & $1973-1994$ & Downward since 1977 \\
\hline Extent of sea ice in the Southern Hemisphere & 1973-1994 & No change, possible decrease between mid 1950 s and early 1970 s \\
\hline Length of the Northern Hemisphere growing season ${ }^{f}$ & $1981-1991$ & $12 \pm 4$ days longer \\
\hline Precipitation ${ }^{\mathrm{g}}$ & 1900-1994 & Generally increasing outside tropics, decreasing in Sahel \\
\hline Heavy precipitation ${ }^{\mathrm{h}}$ & $1910-1990^{\mathrm{i}}$ & Growing in importance \\
\hline Antarctic snowfall & Recent decades & $5-20 \%$ increase \\
\hline Global mean sea level ${ }^{\mathrm{k}}$ & Last century & $1.8 \pm 0.7 \mathrm{~mm} /$ year \\
\hline
\end{tabular}

a Jones et al. (1997a).

b Oerlemans (1994).

c Groisman et al. (1994).

d Maslanik et al. (1996).

e Stammerjohn and Smith (1997); de la Mare (1997).

f Myneni et al. (1997).

g IPCC (1996a).

h Karl et al. (1995); Suppiah and Hennessy (1999).

i Shorter records in some regions.

j Walsh (1995).

k Douglas (1991). 
growth rate in corals, and characteristics of annual layers in ice cores. The reconstructed variation in Northern Hemisphere mean annual temperature is shown in Fig. 2. The number of available climatic indicators decreases the further back in time one goes, from 112 indicators for the period $1820-1980$, to only 22 indicators for the period 1400-1450. In addition, there are various assumptions (e.g., that climatic change and the indicators are linearly related) that also introduce uncertainties into the reconstruction. The error bars in Fig. 21 show the range within which the true annual temperature variations are estimated to fall with a probability of $96 \%$. The reconstruction indicates that the twentieth century has been warmer than at any time since 1400. Furthermore, the years 1990, 1995, and 1997 (not shown) are estimated to have been warmer than any other year since 1400 with a probability of $99.7 \%$.

\subsection{Predictions of future climate}

\subsubsection{Climate feedbacks}

Numerous aspects of the climate system and its response to a change in radiative forcing are still quite uncertain. Many of the uncertainties are due to an insufficient understanding of the interactive climate feedback processes that are key to determining the extent of the climate response to a given change in climate forcing. The feedback processes determine whether the climate amplifies (through positive feedbacks) or reduces (through negative feedbacks) the expected warming from an increase in radiative forcing (Cess and Potter, 1988; IPCC, 1990, 1996a; Mahlman, 1992).

Among the important feedbacks which have to be considered in the calculation of global mean climatic change are the following:

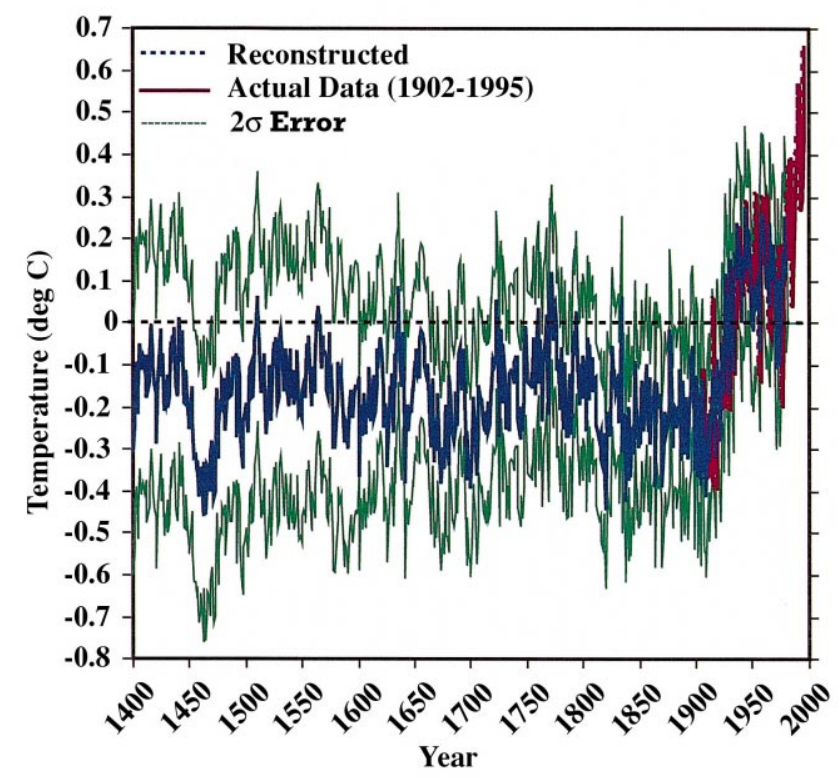

Fig. 21. Reconstructed variation in Northern Hemisphere mean annual temperature based on proxy data. Based on Mann et al. (1998).
1. Water vapor amount: in a warmer climate the atmospheric concentration of water vapor will increase. Because water vapor is a greenhouse gas, this is a positive feedback.

2. Clouds: changes in clouds are difficult to calculate reliably. Because clouds have a strong radiative effect, they are likely to cause a noticeable feedback. This feedback depends on changes in the amount, altitude, and characteristics of the clouds, as well as on the reflectivity of the underlying surface. Hence, even the sign of the feedback is uncertain.

3. Areal extent of ice and snow: as climate warms, a reduction in the area of sea ice and seasonal snow cover on land will reduce the surface reflectivity, thereby tending to produce greater warming, which is a positive feedback.

4. Vegetation: changes in the distribution of different biomes or in the nature of vegetation within a given biome can also lead to changes in the surface reflectivity. This exerts a feedback effect on climatic change, the sign of which depends on whether surface reflectivity is increased or decreased.

5. The carbon cycle: The effect of climate on the terrestrial biosphere and the oceans is likely to alter the sources and sinks of $\mathrm{CO}_{2}$ and $\mathrm{CH}_{4}$, leading to changes in their atmospheric concentrations and hence causing a radiative feedback which may be positive or negative.

Current models of climatic processes indicate that the net effect of the feedbacks being considered in these models is an amplification in projected surface temperature change ranging from a factor of 1 (i.e., no major amplification) to a factor of 3 (IPCC, 1990, 1992, 1996a). Another way of representing the uncertainty in the response of the climate system to changes in radiative forcing is to base it on the equilibrium surface temperature calculated by climate models for a doubling of the atmospheric $\mathrm{CO}_{2}$ concentration. Recent climate model calculations estimate this range at $1.5-4.5^{\circ} \mathrm{C}$ (IPCC, 1990, 1992, 1996a,b), with a best case estimate of $2.5^{\circ} \mathrm{C}$ (Hoffert and Covey, 1992; IPCC, 1992, 1996a).

\subsubsection{Modeling the climate system}

A climate system model is a mathematical representation of the natural processes, interactions, and components that determine the Earth's climate. Climate system models can be used to reproduce past climatic changes, to simulate many features of present-day climatic variability, and to project future climatic change resulting from anthropogenic emissions of greenhouse gases and aerosol particles.

In principle, climate system models are based on fundamental laws of physics and chemistry. The most complex climate models are coupled atmosphere/ocean 
general circulation models (A/O GCMs). These models compute evolving climatic variables such as temperature, wind speed, ocean currents, and precipitation in three dimensions, using fundamental principles of physical science such as conservation of mass, momentum, and energy. In this sense, climate system models differ from purely statistical models used in some of the social sciences, which are based on correlations unrelated to an underlying body of physical law. Nevertheless, all climate system models employ empirical relationships known as 'parameterizations' to some extent in order to represent processes that occur at scales too small to be resolved by the model. The treatment of cloud processes is a prime example of parameterization.

The major components of a climate system model that are important for climatic changes and sea level rise during the next century - the atmosphere, oceans, terrestrial biosphere, and ice sheets - can each be represented by models of varying complexity. That is, for each component, a hierarchy of models can be identified. The main differences between models within a given hierarchy are: (1) the number of spatial dimensions in the model; (2) the extent to which physical processes can be explicitly represented; (3) the level at which empirical parameterizations are introduced; and (4) the computational cost of running the model. In comprehensive models that link several components together, one strives for compatibility between the individual components in terms of detail and dimensionality.

\subsubsection{Climate model projections}

4.3.3.1. GCMs. A wide range of models exists to project future climatic change resulting from anthropogenic emissions of greenhouse gases and aerosol particles. The GCMs attempt to synthesize existing knowledge of the physical and dynamical processes in the overall climate system and try to account for the complex interactions between the various processes. These models combine well-established scientific laws with empirical knowledge and parameterized representations of atmospheric and oceanic processes, as described above. Recent climate model calculations include coupling with ocean models and land process models to include three-dimensional representations of the atmosphere, oceans, cryosphere and land surface. These models can represent on average most of the features of the current climate. Large-scale distributions of pressure, temperature, winds and precipitation are well represented spatially and seasonally. In recent years, GCM climate models are being applied extensively to analyses of transient or time-dependent variations in climate change (Cubasch et al., 1992, 1995; IPCC, 1992, 1996a; Manabe and Stouffer, 1993; Meehl et al., 1993, 1994; Mitchell et al., 1995a, b; Santer et al., 1994, 1995; Haywood et al., 1997; Le Treut et al., 1998). Although GCMs and coupled models are attractive for these purposes, complex models are computationally costly, sometimes difficult to understand, and require high resolution data inputs, which in some cases simply does not exist. They also produce outputs that contain substantial temporal and spatial variability (sometime referred to as 'noise'). This makes analysis of their results a complicated task, as is the case for the real climate system. Results from these models are similar to the results from the simpler models described next.

4.3.3.2. Simple climate models. To thoroughly explore all the possible scenarios and the effects of model assumptions and approximations, simpler models are often used to examine the time-dependent changes. These models represent only the most critical processes. However, simple models can give results similar to GCMs by tying them to the results of complex models. In addition, they can also be directly calibrated against observations. As a result of their simplifications, these models are relatively easy to understand and inexpensive to run, so that multiple diagnostic tests can be executed. One such simple model is the upwelling diffusion model of Jain et al. (1994). It has been used in this analysis to estimate the global mean temperature changes for the IPCC IS92a and IS92c scenarios described earlier, and shown in Fig. 22. Modeled changes in surface temperature for these scenarios are highly dependent on the assumed climate sensitivity. A climate sensitivity of $2.5^{\circ} \mathrm{C}$ for a doubling of $\mathrm{CO}_{2}$ results in a warming by 2100 , relative to 1990 , of about $1.3^{\circ} \mathrm{C}$ for scenario IS $92 \mathrm{c}$ and $2.1^{\circ} \mathrm{C}$ for scenario IS92a. In scenario IS92a, a warming of $2^{\circ} \mathrm{C}$ relative to the pre-industrial atmosphere is exceeded as early as 2040 and 2070 for the climate sensitivities of 4.5 and $2.5^{\circ} \mathrm{C}$, respectively. Although $\mathrm{CO}_{2}$ emissions are dominant, the non- $\mathrm{CO}_{2}$ greenhouse gases are responsible for about $30 \%$ of the global warming. Similar results are found by the models presented in IPCC (1996a).

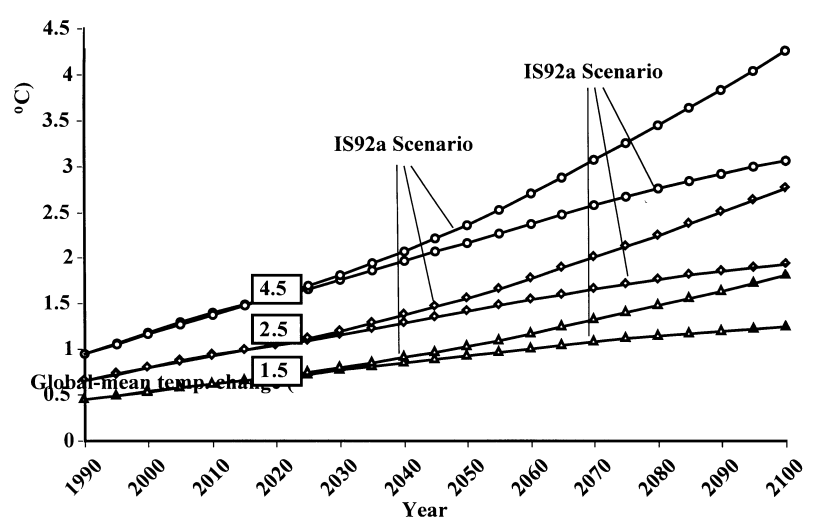

Fig. 22. Climate model-estimated change in global mean surface temperature for greenhouse gas emissions from IPCC scenarios IS92a and IS92c, including effects of the uncertainty range in climate sensitivities $\left(1.5,2.5\right.$, and $4.5^{\circ} \mathrm{C}$ for doubling of $\mathrm{CO}_{2}$ concentration). 


\section{Potential impacts of climate change}

A great deal of work has been undertaken to assess the potential consequences of climate change. This literature is summarized in IPCC (1996b). Since this literature is also summarized in Kickert et al. 1999, we restrict our discussion to the most minimal observations, with a summary of potential impacts given in Table 6.
To begin, anthropogenic climate change is an intergenerational phenomenon. The benefits of emissions mitigation undertaken by the present generation will accrue largely to persons living in the second half of the twenty-first century. At this time, regardless of whether human activities have led to present concentrations of greenhouse gases which are associated with a climate different from that which prevailed at the end of the nineteenth century, there is virtually nothing that the

Table 6

Summary of potential impacts of climate change by sector (based on IPCC, 1996b)

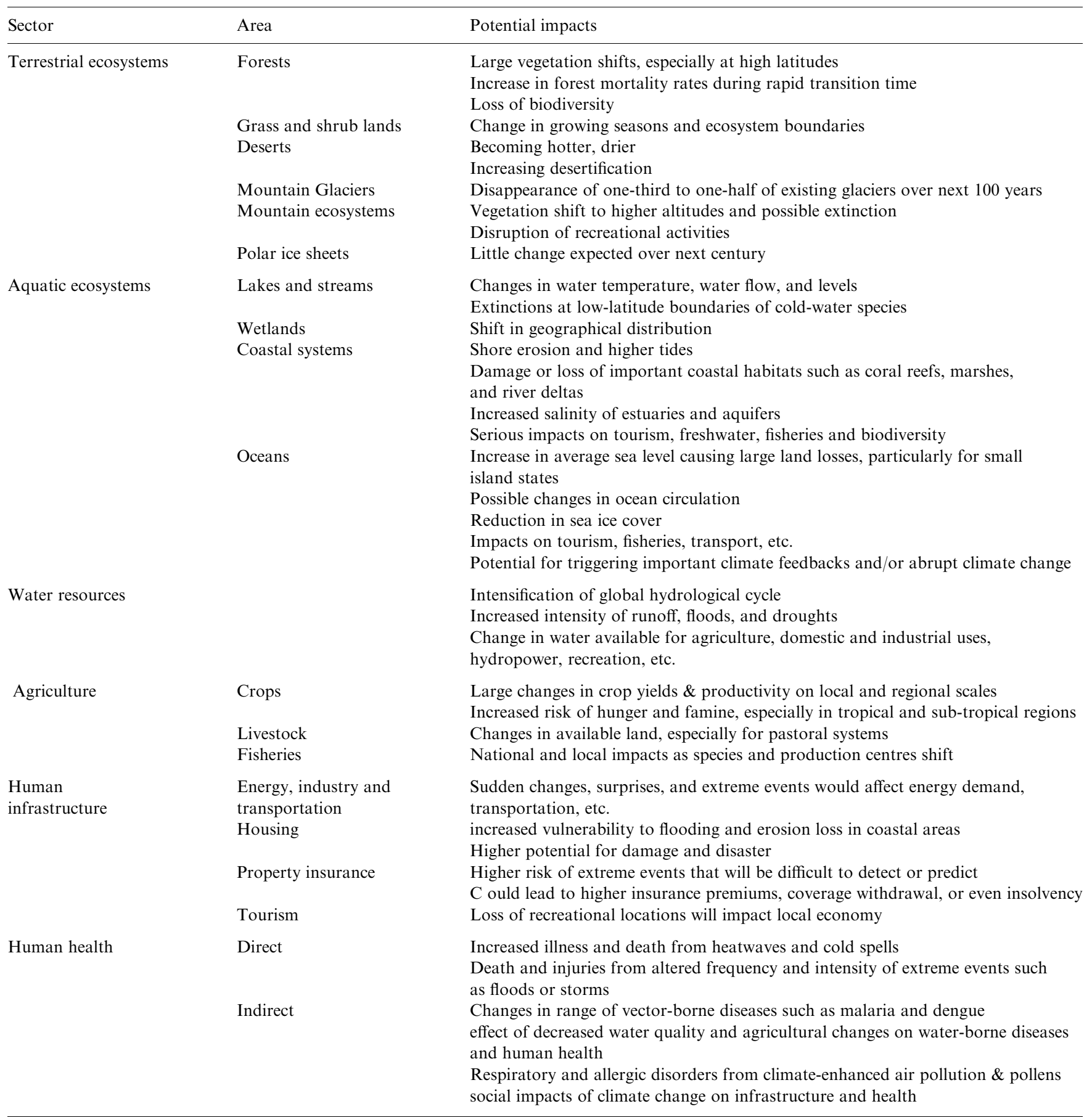


present generation can do to significantly alter that inheritance.

The future consequences of changes in climate relative to present conditions can be disaggregated into impacts that are directly associated with markets (e.g. agriculture, forestry, water supply, space heating and cooling, transportation, sea level rise), and those which are not (e.g. ecosystems, human health, amenity value). The literature shows a variety of different methods for estimating climate change impacts at the present time. These methods include imposing an altered, steady-state climate on the present economy and ecology, with and/ or without adaptive behavior. The problem of estimating the consequences of a climate change experienced at a future time by future populations, economies, and ecosystems has also been addressed, but it is significantly more difficult and results are less certain.

Estimates of the cost of these impacts vary greatly. Legitimate scholars have made cases for global economic damages from a $2^{\circ} \mathrm{C}$ temperature change that range everywhere from significant damages to significant net benefits. The largest sources of uncertainty in estimates of the cost of climate change are associated with effects that do not pass through markets. As the assumed climate change becomes larger, the case for net damages becomes clearer.

The large-scale, steady-state consequence of climate change on ecosystems is reasonably simple to define. Ecosystems associated with high latitudes and altitudes will ultimately be driven to extinction with sufficient warming. However, the timing and regional pattern of changes for flora and fauna remain poorly defined.

Perhaps most daunting is the prospect for surprise. Changing the large-scale energy balance for the planet may lead to sudden, unanticipated, and catastrophic consequences. Although the probabilities appear to be low, potential candidates include sudden destabilization of the West Antarctic ice sheet, run-away climate change $^{8}$ and a shut-down of ocean circulation. Although these examples appear to be highly unlikely, concern about climate change surprises stems less from the prospect of potential catastrophes that have been identified, than from the prospect of unanticipated events. An analogy with global ozone change is the surprising discovery in 1985 of the ozone 'hole' over Antarctica mentioned previously.

\section{Climate policy}

Climate change is unique among environmental issues. Relevant emissions involve a broad array of

\footnotetext{
${ }^{8}$ For example, climate change could lead to a destabilization of hydrates containing $\mathrm{CH}_{4}$, which if released suddenly would lead to massive changes in radiative forcing. However, Harvey and Huang (1995) have suggested this is unlikely.
}

human activities, including agriculture, land-use, and all human activities which produce or consume energy. Greenhouse gases concentrations are affected by the sum of all global emissions over all sources over all parts of the world. Further, the concentration at the end of the next century depends to a first approximation on the sum of all emissions over all years. ${ }^{9}$ Framing an appropriate response to the climate change issue provides a unique set of challenges.

The Framework Convention on Climate Change (FCCC; United Nations, 1992), signed by more than 155 nations, has as its ultimate objective, “... stabilization of greenhouse gas concentrations in the atmosphere at a level that would prevent dangerous anthropogenic interference with the climate system." (p. 5). This goal leaves the precise concentration to be defined at a later date. No concentration objective had been identified after the first three meetings of the parties to the convention.

As discussed earlier, each of the greenhouse gases has its own relationship between emissions and concentration. For gases that are destroyed in the atmosphere, constant emissions are associated with constant steadystate concentrations. Selecting a steady-state concentration for stabilization is equivalent to selecting a global steady-state emission rate. For $\mathrm{CO}_{2}$, the relationship is more complex. A variety of $\mathrm{CO}_{2}$ concentration ceilings and associated global net emissions trajectories have been considered. Those of Wigley et al. (1996) are displayed in Fig. 23. From these figures, it is obvious that, regardless of ceiling, global emissions initially increase, reach a maximum some time in the next century, and eventually begin a long-term decline that continues through the remainder of the analysis period out to 2300. While emissions must eventually peak and decline, fossil fuel carbon need not. Technologies that capture and sequester carbon can provide a mechanism by which fossil fuels could continue to play an important role in future global energy systems without concurrent emissions growth. ${ }^{10}$

\footnotetext{
${ }^{9}$ For a given total emission, the concentration in 2100 will be lower if emissions are released earlier.

${ }^{10}$ Carbon could either be captured from the exhaust gas stream or taken from fossil fuels in a refining process. This would leave either pure hydrogen or a fuel with a higher hydrogen-to-carbon ratio. Several large reservoirs are potentially available:
}

Estimates of global carbon storage reservoirs Carbon storage reservoir Low

Deep ocean 1391

Deep aquifers

Depleted gas reservoirs

Depleted oilreservoirs

87

Source: Hertzog et al. 1997)

In addition, soils represent a potential reservoir that could provide a century scale uptake on the order of 40-80GtC (IPCC, 1996a). Annual rates could be greater than $1 \mathrm{GtC} /$ year in the initial periods. 

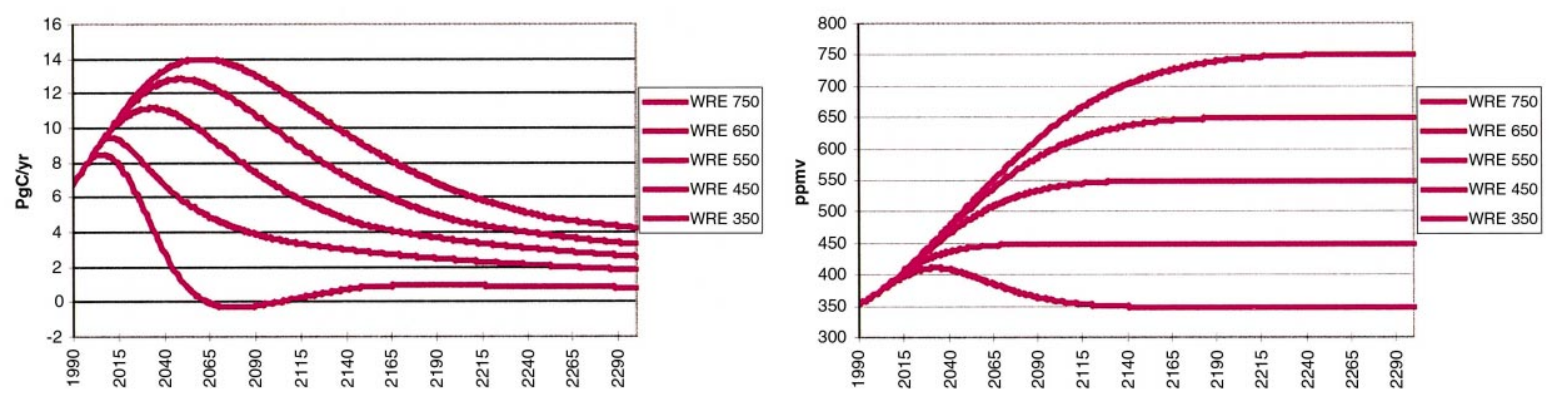

Fig. 23. $\mathrm{CO}_{2}$ concentration ceilings and associated global net emissions (Source: Wigley et al., 1996).

At the third conference of the parties to the FCCC in December 1997, the Kyoto Protocol (United Nations, 1997) was negotiated by over 130 nations as a response to the climate change issue. One of the most prominent features of the agreement is the obligation of parties included in Annex $\mathrm{B}^{11}$ to constrain their emissions of a basket of greenhouse gases including $\mathrm{CO}_{2}, \mathrm{CH}_{4}, \mathrm{~N}_{2} \mathrm{O}$, $\mathrm{SF}_{6}, \mathrm{HFCs}$, and PFCs. In total these nations agreed to reduce their emissions to $5.2 \%$ below 1990 levels on average during the period 2008-2012. Should the Protocol enter into force, and even if its terms were renewed throughout the remainder of the twenty-first century, it would not achieve the goal of the FCCC. As Fig. 24 illustrates, it would not stabilize the concentration of $\mathrm{CO}_{2}$. The Protocol would delay the date by which a concentration of 550 ppmv was exceeded by less than a decade. And it would reduce the year 2100 concentration by less than 55 ppmv. ${ }^{12}$

Whether or not the Kyoto Protocol ever enters into force, more will be needed to achieve the objective of the FCCC. The cost of emissions abatement is a major consideration in determining the degree and timing of regional and global greenhouse gas emissions mitigation. Considerable work has been undertaken to explore the major factors affecting costs of achieving alternative objectives. Cost depends on a wide array of factors. These include the policy instrument employed, the

\footnotetext{
11 The nations included in Annex B are: Australia, Austria, Belgium, Bulgaria, Canada, Croatia, Czech Republic, Denmark, Estonia, European Community, Finland, France, Germany, Greece, Hungary, Iceland, Ireland, Italy, Japan, Latvia, Liechtenstein, Lithuania, Luxembourg, Monaco, Netherlands, New Zealand, Norway, Poland, Portugal, Romania, Russian Federation, Slovakia, Slovenia, Spain, Sweden, Switzerland, Ukraine, UK and Northern Ireland, and the USA.

12 We model the impact of the Kyoto Protocol by taking the IPCC IS92a scenario as a reference case. We then hold emissions in Annex B nations to levels defined in the Protocol, with a linear interpolation of emissions starting in 2005. We assume that non-Annex B emissions are unaffected by the action of Annex B nations. While the non-interaction assumption may be a reasonable first approximation, the potential for emitting activities to migrate from Annex B nations to nonAnnex B nations is a serious concern. Depending on the degree to which this occurs, the effectiveness of the Kyoto Protocol would be reduced.
}

degree of emissions mitigation required, and the timing over which emissions mitigation must occur.

The cost of achieving fossil fuel emissions abatement for a variety of models is shown in Fig. $25 .{ }^{13}$ These analyses implicitly represent an estimate of the minimum cost of achieving various reductions relative to a reference emission. These analyses also assume substantial lead-time to achieve a certain mitigation objective at a single point in time.

The cost of achieving any concentration ceiling is minimized when the value of the last tonne of gas emitted is equal everywhere and over all time. It is easier to construct an agreement that minimizes cost in theory than in practice. In principle, it would be possible to allocate cumulative global emissions for the next century. Values taken from Wigley et al. (1996) are shown in Table 2. In principle, these emissions allowances could be used by parties or traded in a market. This trade would lead to marginal costs being equated across all regions. If owners of the allowances treated the allowance as any other financial asset, they would hold allowances as long as the expected price was rising more rapidly than the rate of return on comparable financial assets. Allowances would be sold off whenever the expected price was rising less rapidly than the rate of return on other assets. This behavior should lead to a situation in which the value of the permits would rise at the rate of interest, producing inter-temporal cost minimization. ${ }^{14}$

The distribution of emissions allowances has income and wealth implications, however. In fact, one of the problems with reaching international agreements on the

\footnotetext{
${ }^{13}$ None of the studies reported here consider carbon capture and sequestration. Furthermore, they do not address either non- $\mathrm{CO}_{2}$ greenhouse gas emissions or non-energy sources.

14 This result needs to be modified by Peck's Law, which states that the rate of increase in the value of an emission allowance should rise at the rate of interest plus the rate of removal of carbon from the atmosphere to long-lived repositories, (Peck and Wan, 1996). Thus, earlier emissions should be discounted at about $6 \%$ per year, $5 \%$ per year which corresponds to the rate of interest plus an additional $1 \%$ per year, which corresponds approximately to the removal rate of the carbon cycle. The initial allocation would also have to be adjusted to allow for a $1 \%$ per year decay rate of the permit allocation.
} 

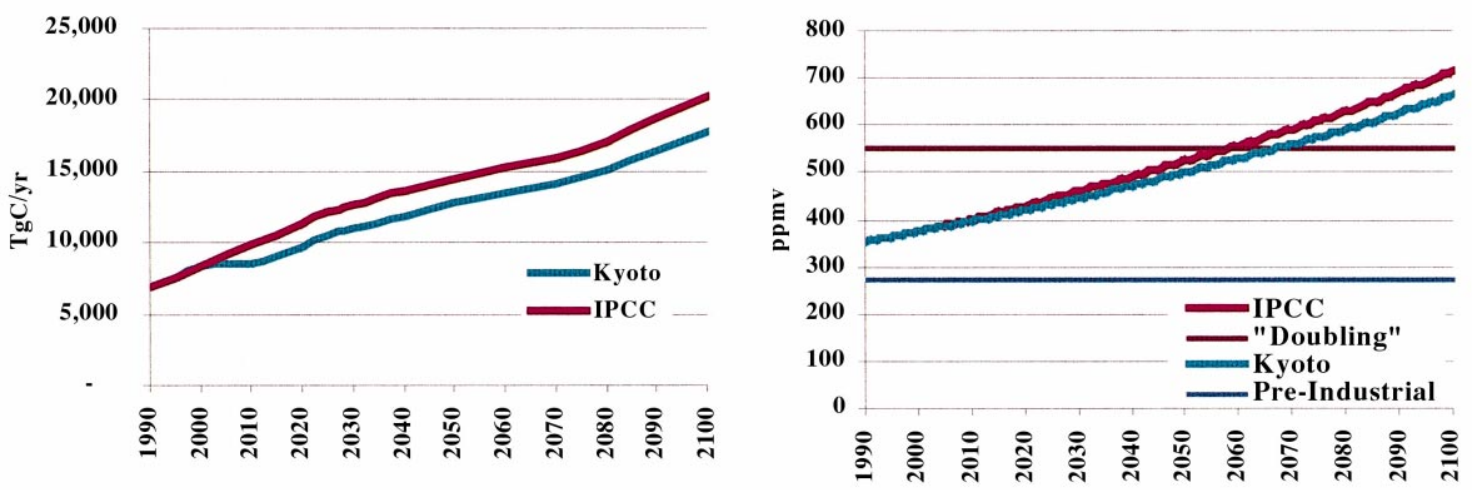

Fig. 24. $\mathrm{CO}_{2}$ concentrations resulting from continuation of Kyoto Protocol emission reductions throughout twenty-first century.

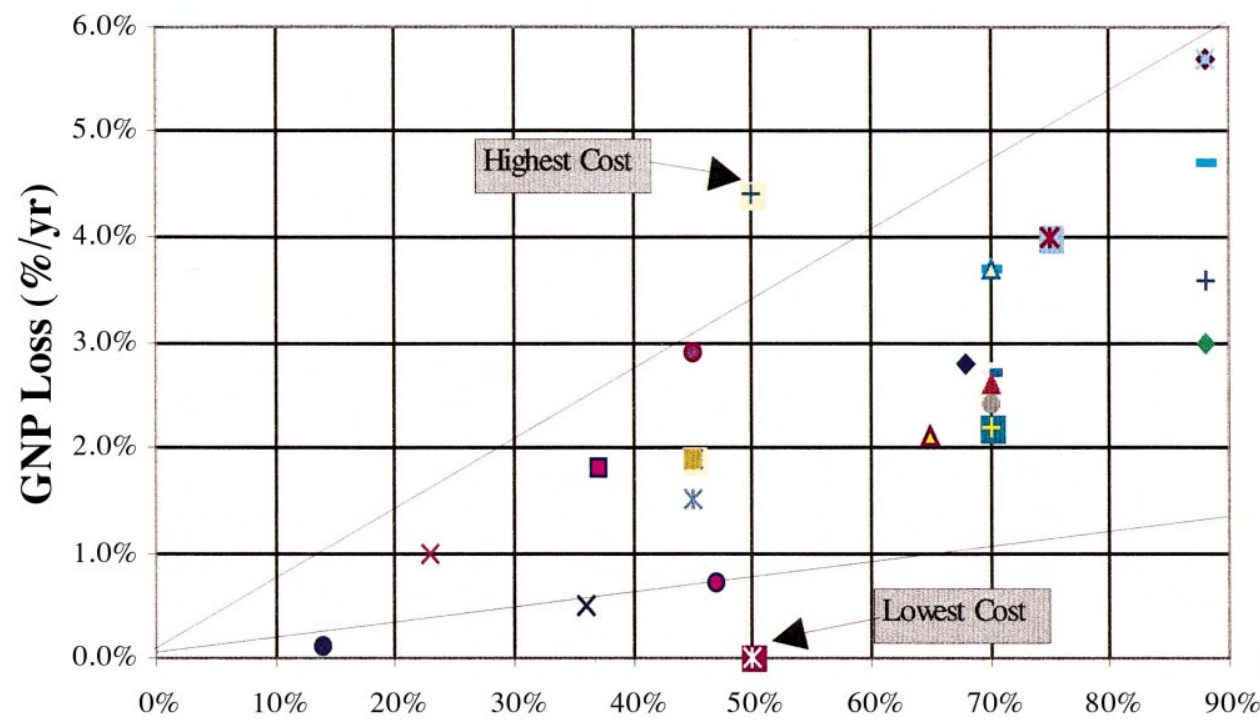

Emission Reduction from Reference Case

\begin{tabular}{|c|c|c|}
\hline - Anderson \& Bird (2050) & 口 Burniaux, et al. (2020) & $\Delta$ Burniaux, et al. (2050) \\
\hline - Edmonds \& Barns (2025a) & X Edmonds \& Barns (2025b) & - Edmonds \& Barns (2025c) \\
\hline \#Edmonds \& Barns (2025d) & * Edmonds \& Barns (2050a) & E Edmonds \& Barns (2050b) \\
\hline$\diamond$ Edmonds \& Barns (2095) & 口 Edmonds \& Barns (2050a) & $\triangle$ Edmonds \& Barns (2050b) \\
\hline × Edmonds \& Barns (2095) & * Manne \& Richels (2100) & - Manne (2020) \\
\hline Manne (2050) & = Manne (2050) & - Manne (2100) \\
\hline$\bullet$ Mintzer (2075) & Oliveira-Martins et al. (2020) & $\mathbf{\Delta}$ Oliveira-Martins et al. (2050) \\
\hline$\times$ Perroni\&Rutherford (2010) & * Rutherford (2020) & Rutherford (2050) \\
\hline + Rutherford (2100) & + Whalley \& Wigle (2030) & X Goldemberg et al. (2020) \\
\hline
\end{tabular}

Fig. 25. Cost of achieving fossil fuel emissions mitigation for a variety of models.

allocation of emissions allowances is that the value of the emissions permits can greatly exceed the cost of mitigation. For poorer countries, the emissions allocation can mean an important source of net income (Edmonds et al. 1995).

There are other real-world problems that also enter. For nations whose participation yields net increases in wealth from the sale of allowances, there is always the problem of 'drop outs.' If the nation sells all of its permits before the end of the allowance period or if the economy transitions from the status of seller to buyer, it may find it advantageous to leave the agreement unless there are deterrent penalties (Cooper, 1996).

An alternative to a global permit-allowance regime is the establishment of a global tax rate for greenhouse gas emissions; but global tax regimes have their own 
difficulties. National governments have jealously guarded the right to tax, and even if governments were able to retain revenues from an exogenously specified tax, they would almost certainly find it difficult to cede the power to regulate taxes and subsidies that would alter the effective rate (Edmonds and Wise, 1998). Another option is a combination of tradable permits and a carbon tax, but applied to national governments rather than individual emitters (Harvey, 1995).

The Kyoto Protocol focuses on actions by nations listed in Annex B. There is a limit to the extent to which these regions, acting alone, can maintain the world on a trajectory that stabilizes the atmosphere. This is shown in Fig. 26. Two alternative emissions trajectories for constructing ceilings for carbon concentrations, Wigley et al. (1996) and IPCC (1995), are displayed. Regardless of the ceiling, even ceilings of 750 ppmv cannot be maintained by Annex B nations alone, even if there is no change in non-Annex $\mathrm{B}$ emissions as a consequence of Annex B mitigation. The Kyoto Protocol obligations are displayed for contrast. ${ }^{15}$ In the long term, atmospheric stabilization is impossible without eventual participation by non-Annex B nations.

Mechanisms that would induce non-Annex B nations to participate over time will be essential to both the physics and economics of the stabilization of greenhouse gas concentrations. This may not be as difficult over time as it might seem. Over the course of the next century, the anticipated growth in emissions from non-Annex B regions is driven, in large part, by increases in income, and income per capita. As the material condition of nonAnnex B populations improves, environmental amenities will rise in priority.

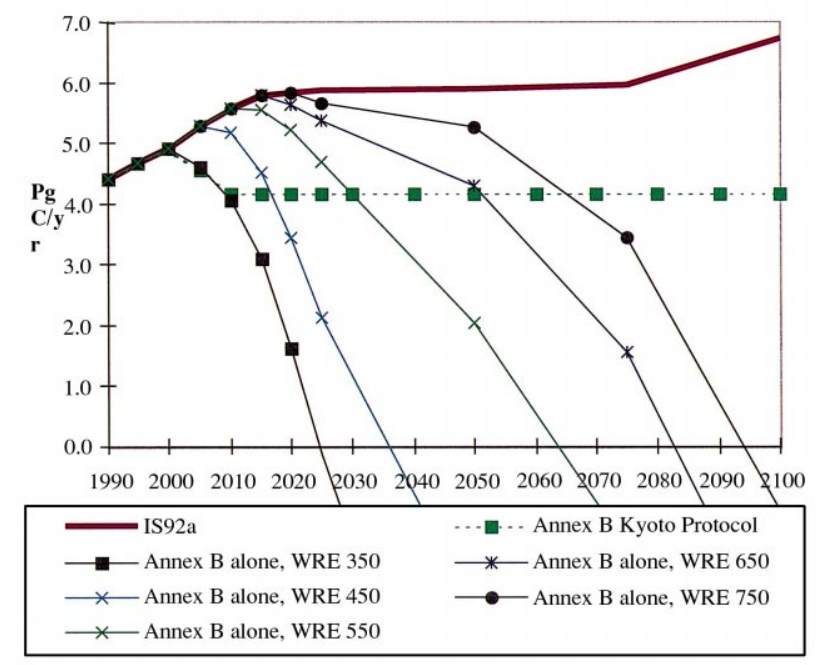

Fig. 26. Carbon emissions pathways necessary to achieve WRE stabilization pathways with emission reductions from Annex B nations alone.

\footnotetext{
${ }^{15}$ Note that the Protocol is only defined for the period 2008-2012, and that we have plotted the Protocol as if it were an obligation that extends throughout the next century.
}

Expanding the set of participants can reduce the cost of emissions mitigation. In principle, non-Annex B nations could be compensated for participation by Annex B nations. The reduction in cost associated with expanded participation in a mitigation regime is well established. The difference between independent compliance and joint compliance on cost has been estimated by a variety of researchers. Richels et al. (1996) showed that the total cost of meeting an obligation could be reduced up to $85 \% .{ }^{16}$ Preliminary analysis of the Kyoto Protocol gives similar results (OECD, 1998; US Government, 1998). These analyses clearly show that the mechanism used to achieve a specific goal can dramatically affect the cost.

\section{Conclusion}

The atmosphere has long been perceived as beyond the realm of human influence. Not until the 1980s was it conclusively shown that stratospheric ozone loss was being caused by CFCs and other man-made halocarbons. This discovery resulted in the first major global attempts to protect the atmosphere from the effects of human activities. Policy actions to protect the ozone layer were relatively straightforward, consisting of controls on emissions of CFCs and other halocarbons that are involved in ozone destruction. These substances are almost entirely produced by the chemical industry, and replacements for the uses of these compounds are being readily found. By controlling the production of ozone-destroying compounds and promoting the use of replacements, the ozone problem is on the way to recovery. Stratospheric ozone is now thought to be at its lowest level and a slow increase is expected over the coming decades as the amount of halocarbons in the atmosphere gradually decreases.

In contrast, climate change is being caused by emissions from a wide range of essential human activities. For example, $\mathrm{CO}_{2}$, the most important greenhouse gas, is produced from fossil fuels, which are the primary source of energy production and transportation for the globe. Although replacement energy sources exist, there are

\footnotetext{
${ }^{16}$ Richels et al. (1996) examined a case in which OECD countries were obligated to return emissions to 1990 levels in the year 2000, and to reduce emissions $20 \%$ below 1990 levels by the year 2010 and emissions could not exceed that level in any subsequent year. The analysis examined compliance through the year 2050. Four modeling groups examined the case. Present discounted total costs, when parties were obligated to meet all obligations through domestic actions, ranged from two to eight trillion dollars, most of which were borne by OECD nations, but some costs were borne by non-participating nations through market interactions. Costs were reduced by approximately $70 \%$ in all models by allowing OECD nations to obtain reductions jointly with all nations of the world. Costs were also reduced by approximately $40 \%$ when nations were allowed to meet obligations on average throughout the entire analysis period. Costs were reduced by approximately $85 \%$ by all models when nations were allowed to meet obligations on average jointly by all nations.
} 
many issues that make it impossible to impose the same type of controls on carbon-containing fuels that were used for CFCs.

Complicating the problem is the fact that the link between climate change and human activities is not as obvious to the popular mind. Evidence is mounting that global warming and other climate changes are already occurring. This paper has shown that climate theory, modeling studies, and long-term measurements combine to provide indisputable evidence for future climate change, and that the potential for serious long-term impacts is great. However, the most significant impacts of climate change are not expected to be seen until decades from now, despite the fact that current emissions of $\mathrm{CO}_{2}$ and other greenhouse gases will be the drivers of future climate change.

Climate change and stratospheric ozone loss are both significant environmental issues in which human activities are affecting the atmosphere in ways that are potentially harmful to human life. However, climate change differs significantly due to the long time scale involved, the comprehensive nature of human activities causing climate change, and the global aspects of its resulting impacts. Because of these issues, it is extremely difficult to develop global policy that will successfully prevent "dangerous anthropogenic interference with the climate system" (United Nations, 1992). Lessons can be learned from the success of ozone-related policy, and some progress toward addressing climate change has been made. However, much larger controls on production and emissions of $\mathrm{CO}_{2}$ and other greenhouse gases will be necessary to avert large changes in climate and associated consequences. The science of global change makes it clear that some adaptation to climate change caused by human activities will be necessary over the next century. The extent of this adaptation will depend on the willingness of the governments of our planet to commit to policies that appropriately weight the costs of reducing greenhouse gases relative to the risks of potential impacts from a changing climate.

\section{Acknowledgements}

At the University of Illinois, this study was supported in part by grants from the US Department of Energy, from the US Environmental Protection Agency and from the National Aeronautics and Space Administration's Atmospheric Chemistry Modeling and Analysis Program.

\section{References}

Andreae, M.O., 1993. Climatic effects of changing atmospheric aerosol levels. In: Henderson-Sellers, A. (Ed.), World Survey of Climatology, Volume XV: Future Climates of the World. Elsevier, Amsterdam.
Bekki, S., Law, K.S., Pyle, J.A., 1994. Effects of ozone depletion on atmospheric $\mathrm{CH}_{4}$ and $\mathrm{CO}$ concentrations. Nature 371, 595-599.

Bernstein, P.M., Montgomery, W.D., 1998. How much could kyoto really cost? A reconstruction and reconciliation of administration estimates. Charles River Associated, Washington, DC.

Bodhaine, B.A., Dutton, E.G., McKenzie, R.L., Johnston, P.V., 1997. Spectral UV measurements at Mauna Loa: July 1995-July 1996. Journal of Geophysical Research 23, 2121-2124.

Booth, C.R., Madronich, S. (1994) Radiation amplification factorsimproved formulation accounts for large increases in ultraviolet radiation associated with Antarctic ozone depletion. In: Weiler, C.S. and Penhale, P.A. (Eds.), Ultraviolet Radiation in Antarctica: Measurements and Biological Effects (AGU Antarctic Research Series, Vol. 62). American Geophysical Union, Washington, DC, pp. 39-42.

Butler, J.H., Elkins, J.W., Hall, B.D., Cummings, S.O., Montzka, S.A., 1992. A decrease in the growth rates of atmospheric halon concentrations. Nature 359, 403-405.

Cess, R.D., Potter, G.L., 1988. A methodology for understanding and intercomparing atmospheric climate feedback processes in general circulation models. J. Geophys. Res. 93, 8305-8314.

Charlson, R.J., Langner, J., Rodhe, H., Leovy, C.B., Warren, S.G., 1991. Perturbation of the Northern Hemisphere radiative balance by backscattering from anthropogenic sulfate aerosols. Tellus $43 \mathrm{~A}-$ B, 152-163.

Charlson, R.J., Schwartz, S.E., Hales, J.M., Cess, R.D., Coakley, J.A. Jr., Hansen, J.E., Hofmann, D.F., 1992. Climate forcing by anthropogenic aerosols. Science 255, 423-430.

Christy, J.R., 1995. Temperature above the surface layer. Climatic Change 31, 455-474.

Christy, J.R., Spencer, R.W., McNider, R.T., 1995. Reducing noise in the MSU daily lower-tropospheric global temperature dataset. J. Climate 8, 888-896.

Christy, J.R., Spencer, R.W., Lobl, E.S., 1999. Analysis of the merging procedure fore the MSU daily temperature time series. J. Climate (in press).

Cooper, R.N., 1997. A Treaty on Global Change: Problems and Prospects. In: Workshop on Design of International Emissions Trading Systems. National Bureau of Economic Research, Snowmass, CO, 13-14 August.

Cubasch, U., Hasselmann, K., Hock, H., Mauer-Reimer, E., Mikolajewicz, U., Santer, B.D., Sausen, R., 1992. Time-dependent greenhouse warming computations with a coupled ocean-atmosphere model. Clim. Dyn. 8, 55-69.

Cubasch, U., Hegerl, G., Hellbach, A., Höck, H., Mikolajewicz, U., Santer, B.D., Voss, R., 1995. A climate simulation starting in 1935. Climate Dynamics 11, 71-84.

Dlugokencky, E.J., Masarie, K.A., Lang, P.M., Tans, P.P., 1998. Continuing decline in the growth rate of the atmospheric $\mathrm{CH}_{4}$ burden. Nature 393, 447-450.

Dlugokencky, E.J., Masaire, K.A., Lang, P.M., Tans, P.P., Steele, L.P., Nisbet, E., 1994. A dramatic decrease in the growth rate of atmospheric $\mathrm{CH}_{4}$ in the northern hemisphere during 1992. Geophys. Res. Lett. 21, 45-48.

Dlugokencky, E.J., Dutton, E., Novelli, P., Tans, P.P., Masarie, K.A., Lantz, K., Madronich, S., 1996. Changes in $\mathrm{CH}_{4}$ and $\mathrm{CO}$ growth rates after the eruption of Mt. Pinatubo and their link with changes in tropical tropospheric UV flux. Geophys. Res. Lett. 23, 2761-2764.

de la Mare, W.K., 1997. Abrupt mid-twentieth-century decline in Antarctic sea-ice extent from whaling records. Nature 389, 57-60.

Douglas, B.C., 1991. Global sea level rise. J. Geophys. Res. 96, 69816992.

Edmonds, J., Reilly, J., 1985. Global Energy: Assessing the Future. Oxford University Press, New York.

Edmonds, J., Wise, M., 1998. Building backstop technologies and policies to implement the Framework Convention On Climate Change. Energy and Environment 9 (4), 383-397. 
Edmonds, J., Wise, M., Barns, D., 1995. Carbon coalitions: the cost and effectiveness of energy agreements to alter trajectories of atmospheric carbon dioxide emissions. Energy Policy 23 (4/5), 309-336.

Elkins, J.W., Thompson, T.M., Butler, J.H., Swanson, T.H., Cummings, S.O., Fisher, D.A., Raffo, A.G., 1993. Decrease in the atmospheric growth rates of CFC-11 and CFC-12. Nature 364, 780-783.

Emanual, W.R., Shugart, H.H., Stevenson, M.P., 1985. Climatic change and the broad-scale distribution of terrestrial ecosystem complexes. Climatic Change 7, 29-43.

Farman, J.C., Gardiner, B.G., Shanklin, J.D., 1985. Large losses of total ozone in Antarctica reveal seasonal $\mathrm{ClO}_{\mathrm{x}} / \mathrm{NO}_{\mathrm{x}}$ interaction. Nature 355, 207-210.

Fioletov, V.E., Evans, W.F.J., 1997. The influence of ozone and other factors on surface radiation. In: Wardle, D.I., Kerr, J.B., McElroy, C.T., Francis, D.R. (Eds.), Ozone Science: a Canadian Perspective on the Changing Ozone Layer. University of Toronto Press, Toronto, pp. 73-90.

Foukal, P., Lean, J., 1990. An empirical model of total solar irradiance variation between 1874 and 1988. Science 247, 556-558.

Gaffen, D.J., 1994. Temporal inhomogeneities in radiosonde temperature records. J. Geophys. Res. 99, 3667-3676.

Groisman, P.Y., Karl, T.R., Knight, R.W., Stenchikov, G.L., 1994. Changes of snow cover, temperature, and the radiative heat balance over the Northern Hemisphere. J. Climate 7, 1633-1656.

Hansen, J., Sato, M., Ruedy, R., 1997. Radiative forcing and climate response. J. Geophys. Res. 102, 6831-6864.

Hansen, J., Lacis, A., Ruedy, R., Sato, M., 1992. Potential climate impact of Mt. Pinatubo eruption. Geophys. Res. Lett. 19, 215218.

Hansen, J., Lacis, A., Ruedy, R., Sato, M., Wilson, H., 1993. How sensitive is the world's climate? National Geographic Research and Exploration 9, 142-158.

Hansen, J., Johnson, D., Lacis, A., Lebedeff, S., Lee, P., Rind, D., Russel, G., 1981. Climate impacts of increasing carbon dioxide. Science 213, 957-966.

Harvey, L.D.D., 1995. Creating a global warming implementation regime. Global Environmental Change 5, 415-432.

Harvey, L.D.D., 1999. Global Warming: The Hard Science. AddisonWesley-Longman, Reading, MA (in preparation).

Harvey, L.D.D., Huang, Z., 1995. Evaluation of the impact of $\mathrm{CH}_{4}$ clathrate destabilization on future global warming. J. Geophys. Res. 100, 2905-2926.

Hayhoe, K.A.S., 1997. A Modelling Study of the Role of $\mathrm{CH}_{4}$ in Global Climate Change. M.S. Thesis, University of Illinois, IL.

Hauglustaine, D.A., Granier, C., Brasseur, G.P., Megie, G., 1994. The importance of atmospheric chemistry in the calculation of radiative forcing on the climate system. J. Geophys. Res. 99, 1173-1186.

Haywood, J.M., Stouffer, R.J., Wetherald, R.T., Manabe, S., Ramaswamy, V., 1997. Transient response of a coupled model to estimated changes in greenhouse gas and sulfate concentrations. Geophys. Res. Lett. 24, 1335-1338.

Hertzog, H., Drake, E., Adams, E., 1997. $\mathrm{CO}_{2}$ Capture, Reuse, and Storage Technologies for Mitigation Global Climate Change. Energy Laboratory, Massachusetts Institute of Technology, Cambridge, MA.

Hoffert, M.I., Covey, C., 1992. Deriving global climate sensitivity from paleoclimate reconstructions. Nature 360, 573-576.

Hoffert, M.I., Caldeira, K., Jain, A.K., Haites, E.F., Harvey, L.D., Potter, S.D., Schlesinger, M.E., Schneider, S.H., Watts, R.G., Wigley, T.M.L., Wuebbles, D.J., 1999. Energy implications of $\mathrm{CO}_{2}$ stabilization. Nature 395, 881-884.

Hogan, K., Harriss, R.C., 1994. Comments on "A dramatic decrease in the growth rate of atmospheric $\mathrm{CH}_{4}$ in the northern hemisphere during 1992" by E. J. Dlugokencky et al.. Geophys. Res. Lett. 21, 2445-2447.

IPCC, 1990. Climate Change: The IPCC Scientific Assessment. Cambridge University Press, Cambridge, UK.
IPCC, 1992. 1992 IPCC Supplement. Cambridge University Press, Cambridge, UK.

IPCC, 1995. Climate Change 1994: Radiative Forcing of Climate Change and An Evaluation of the IPCC IS92 Emissions Scenarios. Cambridge University Press, Cambridge, UK.

IPCC, 1996a. Climate Change 1995:The Science of Climate Change. Contribution of Working Group I to the Second Assessment Report of the Intergovernmental Panel on Climate Change. Cambridge University Press, Cambridge, UK.

IPCC, 1996b. Climate Change 1995: Impacts, Adaptation, and Mitigation of Climate Change: Scientific-Technical Analysis. The Contribution of Working Group II to the Second Assessment Report of the Intergovernmental Panel on Climate Change. Cambridge University Press, Cambridge, UK.

IPCC, 1996c. Climate Change 1995: Economic and Social Dimensions of Climate Change. The Contribution of Working Group III to the Second Assessment Report of the Intergovernmental Panel on Climate Change. Cambridge University Press, Cambridge, UK.

Jain, A.K., Kheshgi, H. S., Wuebbles, D. J., 1994. Integrated Science Model for Assessment of Climate Change. Model presented at and published in the proceedings of Air and Waste Management Association's 87th Annual Meeting, Cincinnati, OH, 19-24 June.

Jain, A.K., Kheshgi, H.S., Wuebbles, D.J., 1996. A globally aggregated reconstruction of cycles of carbon and its isotopes. Tellus 48B, 583-600.

Jones, P.D., 1994. Hemispheric surface air temperature variations: a reanalysis and an update to 1993. J. Climate 10, 1794-1802.

Jones, P., 1998. It was the best of times, it was the worst of times. Science 280, 544-545.

Jones, P.D., Osborn, T.J., Briffa, K.R., 1997a. Estimating sampling errors in large-scale temperature averages. J. Climate 10, 25482568.

Jones, P.D., Osborn, T.J., Wigley, T.M.L., Kelly, P.M., Santer, B.D., 1997b. Comparisons between the microwave sounding unit temperature record and the surface temperature record from 1979 to 1996: real differences or potential discontinuities? J. Geophys. Res. $102,30,135-30,145$.

Jones, P.D., Briffa, K.R., Barnett, T.P., Tett, S.F.B., 1998. Highresolution paleoclimatic records for the last millenium: interpretation, integration and comparison with General Circulation Model control run temperatures. The Holocene 8, 467-483.

Karl, T.R., Knight, R.W., Plummer, N., 1995. Trends in high-frequency climate variability in the twentieth century. Nature 377 , 217-220.

Keeling, C.D., Whorf, T.P., 1998. Atmospheric $\mathrm{CO}_{2}$ concentrationsMauna Loa Observatory, Hawaii, 1958-1997. Available at: http:// cdiac.esd.ornl.gov/ftp/ndp001/maunaloa.txt.

Keeling, C.D., Bacastow, R.B., Bainbridge, A.E., Ekdahl, C.A., Guenther, P.R., Waterman, L.S., Chin, J.F., 1976. Atmospheric carbon dioxide variations at Mauna Loa Observatory, Hawaii. Tellus 28, 538551.

Keller, C.F., 1998. Global Warming: an Update. Los Alamos National Laboratory report.

Kerr, R.A., 1998. Among global thermometers, warming still wins out. Science 281, 1948-1949.

Khalil, M.A.K., Rasmussen, R.A., 1992. The global sources of nitrous oxide. J. Geophys. Res. 97, 14651-14660.

Khalil, M.A.K., Rasmussen, R.A., 1993. Decreasing trend of methane: unpredictability of future concentrations. Chemosphere 26, 803-814.

Khalil, M.A.K., Rasmussen, R.A., 1994. Global emissions of $\mathrm{CH}_{4}$ during the last several centuries. Chemosphere 29, 833-842.

Kickert, R.N., Tonella, G., Simonov, A., Krupa, S.V., 1999. Predictive modeling of effects under global change. Environ. Pollution 100 (1-3), 87-132.

Kiehl, J.T., Briegleb, B.P., 1993. The relative role of sulfate aerosols and greenhouse gases in climate forcing. Science 260, 311-314. 
Lacis, A.A., Wuebbles, D.J., Logan, J.A., 1990. Radiative forcing of climate by changes in the vertical distribution of ozone. J. Geophys. Res. 95, 9971-9981.

Le Treut, H., Forichon, M., Boucher, O., Li, Z.-X., 1998. Sulfate aerosol indirect effect and $\mathrm{CO}_{2}$ greenhouse forcing: equilibrium response of the LMD GCM and associated cloud feedbacks. J. Climate $11,1673-1684$.

Leggett, J., Pepper, W.J., Swart, R.J. Edmonds, J., Meira Filho, L.G., Mintzer, I., Wang, M.X., Wasson, J., 1992. Emissions scenarios for the IPCC: an update. In Climate Change 1992: The Supplementary Report to the IPCC Scientific Assessment. University Press, Cambridge, UK.

Madronich, S., McKenzie, R. L., Bjorn, L. O., Caldwell, M.M., 1998. Changes in biologically active ultraviolet radiation reaching the Earth's surface (Chapter 1). In: van der Leun, J.C., Tang, X., Tevini, M. (Eds.), Environmental Effects of Ozone Depletion, 1998 Update. United Nations Environment Programme, Nairobi. Elsevier, Lausanne.

Mahlman, J.D., 1992. "Assessing global climate change: when will we have better evidence". In: Rosen, L., Glasser, R. (Eds.), Climate Change and Energy Policy. American Inst. of Physics, New York.

Manabe, S., Stouffer, R.J., 1993. Century-scale effects of increased atmospheric $\mathrm{CO}_{2}$ on the oceanatmosphere system. Nature 364, 215 218.

Mann, M.E., Bradley, R.S., Hughes, M.K., 1998. Global-scale temperature patterns and climate forcing over the past six centuries. Nature 392, 779-787.

Maslanik, J.A., Serreze, M.C., Barry, R.G., 1996. Recent decreases in Arctic summer ice cover and linkages to atmospheric circulation changes. Geophys. Res. Lett. 23, 1677-1680.

Mayer, B., Seckmeyer, G., Kylling, A., 1997. Systematic long-term comparison of spectral UV measurements and UVSPEC modeling results. J. Geophys. Res. 102, 8755-8767.

McKenzie, R.L., Johnston, P.V., Bodeker, G.E., Kotkamp, M., Bodhaine, B.A., Hofmann, D.J., Dutton, E.G., Schnell, R.C., Barnes, J.E., Ryan, S.C., 1997. UV spectral irradiance comparison and contrast between Mauna Loa observatory, Hawaii, and Lauder, New Zealand. In: Bojkov, R.D. and Visconti, G. (Eds.) Proceedings of the XVIII Quadrennial Ozone Symposium, Parco Scientifico e Technologico d'Abruzzio, L'Aquila, Italy pp. 857-860.

McPeters, R.D., Hollandsworth, S.M., Flynn, L.E., Herman, J.R., Seftor, C.J., 1996. Long-term trends derived from the 16-year combined Nimbus 7/Meteor 3 TOMS Version 7 record. Geophys. Res. Lett. 23, 3699-3702.

Meehl, G.A., Washington, W.M., Karl, T.R., 1993. Low frequency variability and $\mathrm{CO}_{2}$ transient climate change. Part 1: time-averaged differences. Clim. Dyn. 8, 117-133.

Meehl, G.A., Wheeler, M., Washington, W.M., 1994. Low frequency variability and $\mathrm{CO}_{2}$ transient climate change. Part 3: intermonthly and interannual variability. Clim. Dyn. 10, 277-303.

Mitchell, J.F.B., Johns, T.J., Gregory, J.M., Tett, S.B.F., 1995a. Climate response to increasing levels of greenhouse gases and sulfate aerosols. Nature 376, 501-504.

Mitchell, J.F.B., Davis, R.A., Ingram, W.J., Senior, C.A., 1995b. On surface temperature, greenhouse gases and aerosols: models and observations. J. Climate 10, 2364-2386.

Molina, M.J., Rowland, F.S., 1974. Stratospheric sink for chlorofluoromethanes: Chlorine-atom catalyzed destruction of ozone. Nature 249, 810-814.

Molnar, G.I., Ko, M.K.W., Zhou, S., Sze, N.D., 1994. Climatic consequences of observed ozone loss in the 1980s: relevance to the greenhouse problem. J. Geophys. Res. 99, 25755-25760.

Montzka, S., Myers, R., Butler, J., Elkins, J., Cummings, S., 1993. Global tropospheric distribution and calibration scale of HCFC-22. Geophys. Res. Lett. 20, 703-706.

Montzka, S.A., Butler, J.H., Myers, R.C., Thompson, T.M., Swanson, T.H., Clarke, A.D., Lock, L.T., Elkins, J.W., 1996. Decline in the tropospheric abundance of halogen from halocarbons: Implications for stratospheric ozone depletion. Science 272, 1318-1322.
Morita, T., and Lee, H.-C. (1998) IPCC SRES Database (Version 0.1). Emission Scenario Database prepared for IPCC Special Report on Emissions Scenarios. Available at: http:www-cger.nies.go.jp/cger-e/ db/ipcc.html.

Myneni, R.B., Keeling, C.D., Tucker, C.J., Asrar, G., Nemani, R.R., 1997. Increased plant growth in the northern latitudes from 19811991. Nature 386, 698-702.

Nakicenovic, N., 1999. Global Reference Emissions Scenarios. Paper presented at the International Conference on Sustainable Future of the Global System, organized by the UNU/IAS and IGES, Tokyo, 23-24 February.

Nakicenovic, N., Victor, N., Morita, T., 1998. Emissions scenarios database and review of scenarios. Mitigation and Adaptation Strategies for Global Change 3 (2-4), 95-131.

Nakicenovic, N., Grubler, H., Ishitani, A., Johansson, T., Marland, G., Moreira, J.R., Rogner, H.-H., 1996. "Energy Primer". In: Watson, R.T., Zinyowera, C.C., Moss, R.H. (Eds.), Climate Change 1995: Impacts, Adaptations and Mitigation of Climate Change: Scientific-Technical Analyses. Cambridge University Press, Cambridge, pp. 75-94.

Nesme-Ribes, E., Ferreira, E.N., Sadourny, R., Le Treut, H., Li, Z.X., 1993. Solar dynamics and its impact on solar irradiance and the terrestrial climate. J. Geophys. Res. 98, 18923-18935.

Oerlemans, J., 1994. Quantifying global warming from retreat of glaciers. Science 264, 243-245.

Parker, D.E., Cox, D.I., 1995. Towards a consistent global climatological rawinsonde data-base. Int. J. Climatology 15, 473-496.

OECD, 1998. Economic Modelling of Climate Change (OECD Workshop Report). Organization for Economic Cooperation and Development, Paris, France.

Peck, S.C., Wan, Y.H,. 1996. Analytic solutions of simple greenhouse gas emission models (Chapter 6). In: Van Ierland, E.C., Gorka, K. (Eds.), Economics of Atmospheric Pollution, Springer Verlag, Berlin.

Penner, J.E., Dickinson, R.E., O’Neill, C.A., 1992. Effects of aerosol from biomass burning on the global radiation budget. Science 256, $1432-1434$

Pielke Sr, R.A., Eastman, J., Chase, T.N., Knaff, J., Kittel, T.G.F., 1998. 1973-1996 trends in depth-averaged tropospheric temperature. J. Geophys. Res. 103, 16,927-16,933.

Prabhakara, C., Iacovazzi, R. Jr., Yoo, J.-M., Dalu, G., 1998. Global warming deduced from MSU. Geophys. Res. Lett. 25, 1927-1930.

Ramanathan, V., Cicerone, R.J., Singh, H.B., Kiehl, J.T., 1985. Trace gas trends and their potential role in climate change. J. Geophys. Res. 90, 5547-5557.

Ramanathan, V., Callis, L., Cess, R., Hansen, J., Isaksen, I., Kuhn, W., Lacis, A., Luther, F., Mahlman, J., Reck, R., Schlesinger, M., 1987. Climate-chemical interactions and effects of changing atmospheric trace gases. Rev. Geophys. 25, 1441-1482.

Ramaswamy, V., Schwarzkopf, M.D., Shine, K.P., 1992. Radiative forcing of climate from halocarbon-induced global stratospheric ozone loss. Nature 355, 810-812.

Richels, R., Edmonds, J., Gruenspecht, H., Wigley, T., 1996. "The Berlin Mandate: The design of cost-effective mitigation strategies." In: Nakicenovic, N., Nordhaus, W.D., Richels, R., Toth, F.L. (Eds.), Climate Change: Integrating Science, Economics and Policy (CP-96-1; pp. 29-48). International Institute for Applied Systems Analysis, Laxenburg, Austria.

Rind, D., Lacis, A., 1993. The role of the stratosphere in climate change. Surveys in Geophysics 14, 133-165.

Rogner, H.-H., 1996. An Assessment of World Hydrocarbon Resources (WP-96-56). International Institute for Applied Systems Analysis (IIASA), Laxenburg, Austria.

Santer, B.D., Bruggemann, W., Cubasch, U., Hasselmann, K., MauerReimer, E., Mikolajewicz, U., 1994. Signal to noise analysis of time dependent greenhouse warming experiments, Part 1: pattern analysis. Clim. Dyn. 9, 267-285. 
Santer, B.D., Taylor, K.E., Wigley, T.M.L., Penner, J.E., Jones, P.D., Cubasch, U., 1995. Towards the detection and attribution of an anthropogenic effect on climate. Clim. Dyn. 12, 77-100.

Schwarzkopf, M.D., Ramaswamy, V., 1993. Radiative forcing due to ozone in the 1980s: dependence on altitude of ozone change. Geophys. Res. Lett. 20, 205-208.

SCOPE, 1992. Effects of Increased Ultraviolet Radiation on Biological Systems. Scientific Committee on Problems of the Environment Secretariat, Paris, France.

SPARC, 1998. Assessment of Trends in the Vertical Distribution of Ozone. Stratospheric Processes And their Role in Climate, Report No. 1 and WMO Ozone Research and Monitoring Report No. 43. Geneva.

Stammerjohn, S.E., Smith, R.C., 1997. Opposing Southern Ocean climate patterns as revealed by trends in regional sea ice coverage. Climatic Change 37, 617-639.

Steele, L.P., Dlugokencky, E.J., Lang, P.M., Tans, P.P., Martin, R.C., Masarie, K.A., 1992. Slowing down of the global accumulation of atmospheric $\mathrm{CH}_{4}$ during the 1980s. Nature 358, 313-316.

Suppiah, R., Hennessy, K.J., 1998. Trends in total rainfall, heavy rain events and number of dry days in Australia, 1910-1990. Int. J. Climatology.

Tans, P.P., Fung, I.Y., Takahashi, T., 1990. Observational constraints on the global atmospheric $\mathrm{CO}_{2}$ budget. Science 247, 1431-1438.

Taylor, K.E., Penner, J.E., 1994. Response of the climate system to atmospheric aerosols and greenhouse gases. Nature 369, 734-737.

United Nations, 1987. Montreal Protocol on Substances That Deplete the Ozone Layer. United Nations, New York, NY.

United Nations, 1992. Framework Convention on Climate Change. United Nations, New York.

United Nations, 1997. Kyoto Protocol To The United Nations Framework Convention On Climate Change. United Nations, New York.

UNEP, 1989. Environmental Effects Panel Report. United Nations Environment Programme, Nairobi, Kenya.

UNEP, 1990. London Amendments to The Montreal Protocol. United Nations Environment Programme, Nairobi, Kenya.

UNEP, 1991. Environmental Effects of Ozone Depletion: 1991 Update. United Nations Environment Programme, Nairobi, Kenya.

UNEP, 1992. Report of the Fourth Meeting of the Parties to the
Montreal Protocol on Substances that Deplete the Ozone Layer, United Nations Environment Programme, Copenhagen, 23-25 November, Nairobi, Kenya.

US Government, 1998. The Kyoto Protocol and the President's Policies to Address Climate Change: Administration Economic Analysis. US Government, Washington, DC.

Walsh, J.E., 1995. Long-term observations for monitoring of the cryosphere. Climatic Change 31, 369-394.

Wang, W.C., Zhuang, Y.C., Bojkov, R.D., 1993. Climate implications of observed changes in ozone vertical distributions at middle and high latitudes of the Northern Hemisphere. Geophys. Res. Lett. 20, $1567-1570$.

Wentz, F.J., Schabel, M., 1998. Effects of orbitsal decay on satellitederived lower-tropospheric temperature trends. Nature 394, 661-664.

Wigley, T.M.L., Richels, R., Edmonds, J., 1996. Economic and environmental choices in the stabilization of atmospheric $\mathrm{CO}_{2}$ concentrations. Nature 379, 240-243.

WMO, 1991. Scientific Assessment of Ozone Depletion, 1991 (WMO Global Ozone Research and Monitoring Project-Report No. 25). World Meteorological Organization, Geneva.

WMO, 1995. Scientific Assessment of Ozone Depletion: 1994 (WMO Global Ozone Research and Monitoring Project, Report No. 37). World Meteorological Organization, Geneva.

WMO, 1998. Scientific Assessment of Ozone Layer: 1998 (WMO Global Ozone Research and Monitoring Project, Report No. 44). World Meteorological Organization, Geneva.

Wuebbles, D.J., Kinnison, D.E., Grant, K.E., Lean, J., 1991. The effect of solar flux variations and trace gas emissions on recent trends in stratospheric ozone and temperature. J. Geomag. Geoelectr. 43, 709-718.

Wuebbles, D. J., Jain, A., Kotamarthi, R., Naik, V., Patten, K. O., 1999. Replacements for CFCs and halons and their effects on stratospheric ozone. In: Nathan, T.R., Cordero, E. (Eds.), Recent Advances in Stratospheric Processes, Research Signpost, India (in press)

Zerefos, C.S., Balis, D.S., Bais, A.F., Gillotay, D., Simon, P.C., Mayer, B., Seckmeyer, G., 1997. Variability of UV-B at four stations in Europe. Geophys. Res. Lett. 24, 1363-1366. 